\title{
Phase and Strain Mapping of a Protective Coating on Carbon-Carbon
}

John Thornton $^{1 *}$, Darren Dale ${ }^{2}$, Jacob Ruff ${ }^{2}$ and Chris Wood ${ }^{1}$

1. Aerospace Division, DST Group, 506 Lorimer Street, Fishermens Bend, Victoria 3207, Australia.

2. CHESS, Cornell University, Ithaca, New York, USA

\begin{abstract}
Carbon-carbon $(\mathrm{C} / \mathrm{C})$ is used in high temperature structures. To prevent rapid oxidation of the carbon, protective coatings are applied. This paper examines such a protective coating with high energy X-ray diffraction. The coating consisted of a $0.01 \mathrm{~mm}$ outer layer of sodium silicate glass on a $0.2 \mathrm{~mm}$ layer of silicon carbide $(\mathrm{SiC})$ with a $0.1 \mathrm{~mm}$ transition layer into the $\mathrm{C} / \mathrm{C}$ of carbon fibres surrounded by a $\mathrm{SiC}$ matrix. It was examined in its pristine state and after heating with an oxy-acetylene torch. An area X-ray detector was used to obtain phase and strain information as a function of depth through the coating. In-plane tensile strains were observed in both a crystalline $\mathrm{SiO}_{2}$ phase and within the $\mathrm{SiC}$ of the transition layer. Oxidation protection was compromised by through-thickness cracks in the SiC layer caused by the large tensile cooling strains in the layer. The strains and the density of the cracking increased after heating. However, several mechanisms were identified that moderated the strains. Based on two of these mechanisms a buffer layer of graphite between the $\mathrm{C} / \mathrm{C}$ and the $\mathrm{SiC}$ was proposed to improve oxidation resistance. The low elastic modulus of the graphite reduces the strains in the SiC coating, which reduces the crack density, which in turn improves oxidation resistance. Adding $\mathrm{SiC}$ fibres to the graphite and $\mathrm{SiC}$ was also proposed to further reduce cracking.
\end{abstract}


Keywords: carbon-carbon; protective coatings; synchrotron radiation; residual stress

*Corresponding author Tel: +61 39626 7311, fax: +61 396267083 Email:

john.thornton@dsto.defence.gov.au 


\section{Introduction}

The low density, high strength at very high temperatures $\left(>2000^{\circ} \mathrm{C}\right)$, and toughness of carboncarbon $(\mathrm{C} / \mathrm{C})$ make it attractive for aerospace applications where high temperatures are experienced e.g. rocket nozzles and leading edges on re-entry vehicles $[1,2]$. However, it is susceptible to oxidation $[1,2]$. Oxidation resistance can be provided by replacing the carbon matrix with silicon carbide ( $\mathrm{SiC}$ ) [1] or by providing a protective coating [1, 2, 3, and 4]. The protective coating may have the benefit of allowing the bulk of the carbon-carbon to retain its high strength at high temperatures [5]. However, because the thermal expansion coefficient of carbon-carbon is lower than most oxidation resistant materials [6], in-plane residual strains will be formed in the coatings; either tensile strains when they cool from their formation temperature or compressive strains when they are heated during service (e.g. during re-entry). Such strains can limit the ability of the coatings to protect the underlying carbon from oxidation. Tensile strains can result in through thickness cracks in the coating that will allow any surrounding oxygen to penetrate directly to the carbon and thus burn it away at high temperatures. Compressive stresses can lead to spalling of the coating which again exposes the carbon to any surrounding oxygen and thus oxidation at high temperatures. Therefore the measurement of the strains in such coatings is an important factor in assessing their fitnessfor-purpose. It is also important to map any variations of the strain in such coatings with depth, particularly as variations are likely at the outer surface and at the coating's interface with its substrate. Such strain measurement and mapping may indicate how oxidation protection might be improved by modifying the composition and structure of the coating and substrate system to reduce strains. High energy X-ray diffraction has been used to study the depth profile of residual strain in coatings $[7,8]$.

We have studied $\mathrm{C} / \mathrm{C}$ with a $\mathrm{SiC}$ conversion coating with and without heating with an oxyacetylene flame. The coating contained through-thickness cracks generated by the thermal 
expansion mismatch between the coating and the $\mathrm{C} / \mathrm{C}$ [2] and was therefore expected to contain residual strains. High energy X-ray diffraction was used to map the phase and residual strains as a function of depth. These maps were complemented with an analysis of the microstructures using scanning electron microscopy (SEM) and energy dispersive X-ray spectroscopy (EDS). The type of $\mathrm{C} / \mathrm{C}$ and coating system studied was employed successfully on the on the leading edges of the Space Shuttle Orbiter $[2,9]$, thus this system, and the strain distributions measured here, provide a baseline against which alternative coatings [3] or improvements can be compared. In the discussion we analyse the origin of the observed residual strains and, based on this analysis, propose methods for reducing the level of strain and the number of through-thickness cracks with the intention of further improving the oxidation resistance. We also discuss how to improve the strain mapping technique and extend it to the carbon substrate. 


\section{Experimental}

\subsection{Samples}

The 30x30x4.8 mm samples studied were cut from a $4.8 \mathrm{~mm}$ thick plate of $\mathrm{C} / \mathrm{C}$ coated with a conversion coating of $\mathrm{SiC}$ and vacuum infiltrated with TEOS (tetra-ethyl orthosilicate) [9]. An example cross-section of the $\mathrm{C} / \mathrm{C}$ is shown in Figure 1. The $\mathrm{C} / \mathrm{C}$ plate consisted of a two dimensional lay-up of sheets of woven carbon fibre bundles. The orientation of the bundles in successive sheets alternated between $+45^{\circ} /-45^{\circ}$ and $0 \% 190^{\circ}$, with the formation of the $\mathrm{SiC}$ consuming the surface $+45^{\circ} /-45^{\circ}$ sheet. Within the $\mathrm{C} / \mathrm{C}$ the bundles of carbon fibres had an elliptical cross-section approximately $0.13 \mathrm{~mm}$ high $\mathrm{x} 1 \mathrm{~mm}$ wide. The individual fibre diameter was about $8 \mu \mathrm{m}$. The manufacturing method is propriety but the $\mathrm{C} / \mathrm{C}$ and coating are similar to the reinforced $\mathrm{C} / \mathrm{C}$ with its $\mathrm{SiC}$ conversion coating that protected the wing leading edge of the Space Shuttle Orbiter [9]. The processing temperature of the SiC coating was $1650^{\circ} \mathrm{C}$, the TEOS is reportedly transformed to $\mathrm{SiO}_{2}$ after a mild heat treatment, and an additional sodium silicate glass coating is applied to the top of the $\mathrm{SiC}$ coating [9]. This glass also contains $\mathrm{SiC}$ particles. The thermal expansion coefficient of this type of $2 \mathrm{D} \mathrm{C} / \mathrm{C}$ is $1.1 \times 10^{-6}[6]$.

The strain mapping was performed on a pristine sample and a heated sample. The heating was performed using an oxy-acetylene flame to heat a circle of about $5 \mathrm{~mm}$ diameter in the centre of the $30 \mathrm{~mm} \times 30 \mathrm{~mm}$ square samples. The peak temperature at the surface was measured as $(1500 \pm 100){ }^{\circ} \mathrm{C}$ by a pyrometer. The difficulty in aligning the pyrometer's line of sight exactly with the peak of the surface temperature distribution was responsible for the large temperature error. The heat flux was $920 \mathrm{Wm}^{-2}$. Following exposure to the flame, the heat affected region was visible to the naked eye. A $3 \mathrm{~mm}$ wide strip was cut from each sample so that the strip contained the bulk of the heat affected region at its centre as shown in 
Figure 2. These strips were used for the high energy diffraction measurements. The visibility of the heated affected region enabled the X-ray beam to be positioned at its centre. A diamond cutting wheel was used to produce the strips and produced little damage. As the damage was limited to less than $0.1 \mathrm{~mm}$ from the cut it was unlikely to have affected the strain distribution through the bulk of the strips.

The chosen $3 \mathrm{~mm}$ width of the strips was a compromise between maintaining representative residual stresses, which required a wide sample, and strain sensitivity, which required a thin sample. Previous strain mapping and finite element calculations work [7] indicated that the strain relaxation would be limited in range to the order of the twice the coating thickness. However, the width could not be increased much beyond $3 \mathrm{~mm}$ without compromising the strain resolution as a wider strip would have broadened the diffraction rings on the X-ray detector. Thus, the $3 \mathrm{~mm}$ width was adequate for measuring representative residual stresses in the $0.2 \mathrm{~mm}$ thick coating and the adjacent $0.2 \mathrm{~mm}$ of substrate, but it was anticipated that any stress measurements from the central portion of the $4.8 \mathrm{~mm}$ thick substrate would be substantially below that found in the centre of a wider sample.

The strips were held in the X-ray beam by clamping them lightly at one end to minimise any disturbance to the stress field measured at the centre of the strips. This did not produce any visual damage to the strips such as extra cracking of the coating.

\subsection{Apparatus}

The strain mapping was performed using high energy X-ray diffraction at the A2 beamline at CHESS at Cornell University in New York State [10]. Figure 3 shows a schematic of the experimental rig; the arrangement is similar to that developed at other synchrotrons $[7,8]$. A $60 \mathrm{keV}$ X-ray beam was passed through the strip producing diffraction cones which were 
registered on a large area X-ray detector as diffraction rings (Fig. 4). Strain free material produced circular diffraction rings (solid circle on the detector in Fig. 3). Strains in the strip distorted the diffraction rings; for instance, a compressive strain in the y-direction would have reduced the atomic spacing in this direction causing the diameter of the rings to increase in this direction (the dotted ellipse in Fig. 3). The Poisson effect will have caused a complementary increase in the atomic spacing and a decrease in ring diameter in the $\mathrm{x}$ direction (also the dotted ellipse in Fig. 3). Measurement of the distortion allowed the strains in the plane parallel to the detector and perpendicular to the X-ray beam to be determined.

It was also possible for the diffraction rings to be distorted by slight tilts in the detector relative to the incident $\mathrm{X}$-ray beam direction. To enable these tilts to be determined and the images adjusted for this systematic distortion a powder sample of ceria [11] was also exposed. Kapton tape was used to fasten the ceria standard on the top of the analysed strips. The ceria spanned the strip in the direction of the X-ray beam which ensured that it covered same span of distance from the detector. The powder did not sustain a macro stress and therefore produced circular diffraction rings. Any distortion then shown on the detector was measured and compensated for by determining the tilt angle, direction and beam centre which made the ceria rings circular.

Collimating the incident X-ray beam down so that its thickness in the vertical direction (x direction in Figs. 2 and 3) was smaller than the coating thickness enabled the strain and phase of the sample to be determined as a function of depth. Each sample was simply stepped in the vertical direction and a diffraction pattern was collected in the detector at each step. To prevent the X-ray beam from sampling diagonally through a range of depths the coating surface was placed parallel to the beam direction and perpendicular to the vertical direction. In these experiments the sample to detector distance was $946.689 \mathrm{~mm}$ for the pristine material 
run and $961.155 \mathrm{~mm}$ for the heated material run. The area X-ray detector employed for both runs consisted of 2048x2048 $0.2 \mathrm{~mm}$ pixels.

The thickness of the X-ray beam in the vertical direction defined the depth resolution. For the pristine sample run this thickness and depth resolution was $0.1 \mathrm{~mm}$. After analysing pristine sample results it was decided that during a second run at CHESS the depth resolution should be reduced to $0.05 \mathrm{~mm}$ by reducing the gap between the slits collimating the beam. This finer depth resolution was used to depth profile the strains in the heated sample. An additional scan was also made through the rear coating during the second CHESS run. This rear coating was visually unaffected by the oxy-acetylene flame.

In addition to diffraction with synchrotron radiation the samples were also imaged and analysed using an SEM (JSM-6490LA from JOEL Japan) and its associated EDS system (a $80 \mathrm{~mm}^{2}$ X-Max by Oxford Instruments U.K. with AZtec software).

\subsection{Data Analysis}

Strain is the change in length divided by the strain-free length. The measurement of strain with X-ray diffraction uses the lattice spacings in crystalline material as atomic sized strain gauges. The relationship between strain, $\varepsilon_{\psi}$, at a particular azimuthal angle, $\psi$ (Fig. 3), and the change in atomic d-spacings producing the diffraction line is:

$$
\varepsilon_{\psi}=\left(\mathrm{d}_{\psi}-\mathrm{d}_{0}\right) / \mathrm{d}_{0}
$$

Where for strain measurements $d_{0}$ is the $d$-spacing of the selected lattice planes when the material is free of strain, and $d_{\psi}$ is the d-spacing of the selected lattice planes, in the strained material, at the azimuthal angle $\psi$ (Fig. 3). In the transmission geometry used one directly 
measures the radius of the diffraction ring which is then converted to the d-spacing responsible for the diffraction. The geometry (Fig. 3) combined with the Bragg equation enabled the atomic $d$-spacing, $d_{\psi}$, to be determined from the radius versus azimuthal data [7]

$$
\mathrm{d}_{\psi}=\lambda /\left\{2 \sin \left[0.5 \arctan \left(\mathrm{r}_{\psi} / \mathrm{L}\right)\right]\right\}
$$

Where $\lambda$ is the $\mathrm{X}$-ray wavelength,

$r_{\psi}$ is the radius of the diffraction line centroid at a given azimuthal angle,

$\mathrm{L}$ is the detector to sample distance, and

$2 \theta=\arctan \left(\mathrm{r}_{\psi} / \mathrm{L}\right)$ in Figure 3.

It is important to note that Figure 3 is a schematic and the distortion of the rings under strain has been exaggerated. The radii of the rings are only changed by amounts of the order of the strains which are typically of the order of $10^{-4}$. Thus some of the actual rings shown in Figure 4 were distorted by strain but it is not visible to the eye.

To improve sensitivity it was necessary to find the centroids of the diffraction lines in the dspacing as a function of $\psi$ to produce plots like Figure 5. After the centroid fitting the twin peaks in Figure 5 that correspond to tension in the plane of the coating can be seen clearly. In comparison, the d-spacing of a strain free $\mathrm{SiC}$ sample would be constant $\left(\mathrm{d}_{0}\right)$, irrespective of position around the diffraction ring, $\psi$. This is shown by the dashed line. The centroid fitting was done in MATLAB by fitting pseudo-Voigt functions using a least squares routine [7]. Centroid fitting is also necessary with conventional laboratory strain measurement [12].

The data processing is described in detail elsewhere [7] and consists of the following stages: alignment using the ceria standard and FIT2d [13]; conversion from radial $(2 \theta, \Psi)$ plots to linear $(2 \theta, \Psi)$ plots by integration with FIT2d [13]; converting $2 \theta$ to d-spacings with Equation 
2 to give linear $\left(\mathrm{d}_{\psi}, \Psi\right)$ plots; finding the centroids of the diffraction lines to give $\left(\mathrm{d}_{\psi}, \Psi\right)$ plots like Figure 5; and finally fitting these $\left(\mathrm{d}_{\psi}, \Psi\right)$ plots with Equation 3 to find the strains and strain free lattice spacing.

$$
\mathrm{d}_{\psi}=\mathrm{A}\left(\cos ^{2} \psi-2 v \sin ^{2} \psi\right)+\mathrm{B} \sin 2 \psi+C
$$

Where $\mathrm{A}$ is $\mathrm{d}_{0} \varepsilon_{\mathrm{y}} ; \mathrm{B}$ is $\mathrm{d}_{0} \varepsilon_{\mathrm{xy}} ; \mathrm{C}$ is $\mathrm{d}_{0}$ and $\mathrm{v}$ is Poisson's ratio.

Equation 3 relied on two assumptions:

1. The strains parallel to the surface of the coating are equal $\left(\varepsilon_{\mathrm{y}}=\varepsilon_{\mathrm{z}}\right)$.

2. That the strains perpendicular to this surface are generated solely from both parallel strains by the Poisson effect $\left(\varepsilon_{\mathrm{x}=}-2 v \varepsilon_{\mathrm{y}}\right)$.

Once $\mathrm{C}$ was determined it could be used with $\mathrm{A}$ and $\mathrm{B}$ and $\varepsilon_{\mathrm{x}}=-2 v \varepsilon_{\mathrm{y}}$ to determine the three strains perpendicular to the beam: $\varepsilon_{\mathrm{x}}, \varepsilon_{\mathrm{y}}$ and $\varepsilon_{\mathrm{xy}}$. The term $\left(\varepsilon_{\mathrm{xy}}\right)$ was the shear component which would have been significant if the principle strains had not been parallel to the $\mathrm{x}$ and $\mathrm{y}$ directions of the detector. The values of $v$ used in this work were 0.188 for $\mathrm{SiC}$ [14] and 0.17 for $\mathrm{SiO}_{2}[14]$.

\section{Results}

\subsection{Microstructure}

\subsubsection{Pristine Material}

The surface of the pristine material (Fig. 6a) was composed of $\mathrm{O}, \mathrm{Si}, \mathrm{C}$ and traces of $\mathrm{Al}$ and $\mathrm{Na}$, and was divided up into a network of cracks evocative of mud-flat cracking. Higher magnification showed it to be composed of small grains of $\mathrm{SiC}$ embedded in a more continuous matrix of mainly $\mathrm{Si}$ and $\mathrm{O}$. The cross-section (Fig. 7a) shows the $\mathrm{SiC}$ coating with a typical through thickness crack and a patchy transition layer between the coating and the $\mathrm{C} / \mathrm{C}$, where some of the $\mathrm{SiC}$ surrounds the carbon fibres to form $\mathrm{C} / \mathrm{SiC}$. The typical thickness 
of the $\mathrm{SiC}$ plus was about $0.2 \mathrm{~mm}$ but the thicknesses of both the $\mathrm{SiC}$ and the transitional $\mathrm{C} / \mathrm{SiC}$ layers varied considerably across the strip. The average crack spacing was about 1.6 $\mathrm{mm}$ which was similar to pitch of the mudflat cracking seen on the surface (Fig. 6a). The SiC coating was composed of the expected $\mathrm{C}$ and $\mathrm{Si}$ but also contained $\mathrm{O}$ and traces of $\mathrm{Al}$ and $\mathrm{Na}$. The penetration of the $\mathrm{O}$ and the $\mathrm{Na}$ indicate that the sodium silicate glass and/or the $\mathrm{SiO}_{2}$ from the TEOS were also major components of the $\mathrm{SiC}$ and $\mathrm{C} / \mathrm{SiC}$ layers. Furthermore, EDS detected $\mathrm{O}$ and $\mathrm{Si}$ in the $\mathrm{C} / \mathrm{C}$ to depths of about $0.3 \mathrm{~mm}$ below the bottom of the $\mathrm{C} / \mathrm{SiC}$ layer. This indicated that the $\mathrm{C} / \mathrm{C}$ here contained traces of either $\mathrm{SiC}$ or $\mathrm{SiO}_{2}$ or both. Some of this this $\mathrm{SiC}$ or $\mathrm{SiO}_{2}$ surrounds carbon fibres (Fig 8a) and forms wavy ribbons (Figs 7a and 8a), the composition of which was confirmed by EDS.

At higher magnification the cross-section (Fig. 9a) showed a $0.02 \mathrm{~mm}$ thick surface layer with $\mathrm{SiC}$ grains connected by a matrix of what EDS indicated was $\mathrm{SiO}_{2}$. The grains in this surface layer were about $10 \mu \mathrm{m}$ long. The $\mathrm{SiC}$ grains in the bulk of the $\mathrm{SiC}$ layer and in the transition region were not easily distinguished but appeared to be less than $1 \mu \mathrm{m}$ long.

Figure 10a shows the elemental depth profiles for $\mathrm{Si}, \mathrm{C}$ and $\mathrm{O}$ given by EDS. The X-ray counts can be used as an approximate guide to the variation of concentration of these elements with depth. The SiC coating was thicker here than the region shown in Figure 7a.

The analyses of both the top surface and of the cross-section were compatible with the descriptions of this type of reinforced carbon/carbon found in the literature [9]. 


\subsubsection{Heated Material}

The microstructure and composition of the heated material, directly under the oxy-acetylene flame, (Figs. 6b, 7b, 8b, 9b and 10b) was similar to that of the pristine material (Figs. 6a, 7a, 8a, 9a and 10a). Both consisted of $\mathrm{SiC}$ and $\mathrm{C} / \mathrm{SiC}$ layers on a $\mathrm{C} / \mathrm{C}$ substrate. However, there were key differences.

1. The heating produced an undulating but smooth surface of $\mathrm{SiO}_{2}$ with pinholes (Figs. $6 \mathrm{~b}$ and $9 \mathrm{~b})$. Few large $\mathrm{SiC}$ grains remained (Fig 9b).

2. In the cross-section view the crack spacing had changed from $1.6 \mathrm{~mm}$ (pristine) to 0.4 mm (heated), and many cracks had become filled with $\mathrm{SiO}_{2}$ (Figs. 7b).

3. A reduction in the amount of $\mathrm{Na}$. Although the surface $\mathrm{Na}$ concentration was unchanged when analysed from above (Figs. $6 \mathrm{a}$ and $6 \mathrm{~b}$ view), the $\mathrm{Na}$ in the bulk of the $\mathrm{SiC}$ layer was reduced by a quarter, and there was no $\mathrm{Na}$ in the $\mathrm{SiO}_{2}$ within the cracks (Fig, 7b).

4. An increase of $x 2.5$ in the $\mathrm{O}$ content down to a depth of $0.8 \mathrm{~mm}$ (Figs 10a and 10b).

It should be noted that outside the central $2 \mathrm{~mm}$ diameter region that had been directly under the oxy-acetylene flame the cross-section appeared similar to that of the pristine material.

Overall the SEM studies showed that the heating increased the amount of oxide, on the surface, in the through-thickness cracks, and within the $\mathrm{C} / \mathrm{C}$. This shows that, during heating with the oxy-acetylene flame, some oxygen penetrated the sodium silicate and reacted with the $\mathrm{SiC}$ to form the observed extra $\mathrm{SiO}_{2} . \mathrm{CO}_{2}$ will have also been formed. The smooth undulating surface after heating indicates that the sodium silicate was fluid under the flame and that many of the large $\mathrm{SiC}$ grains were oxidised. The pinholes were relics of bubbles rising through the fluid silicate as the $\mathrm{CO}_{2}$ escaped. It appears that on cooling, much of the oxide was initially fluid and was therefore able to fill the through-thickness cracks in the SiC 
coating that opened up as the coating contracted. This would have prevented the oxidation of the underlying $\mathrm{C} / \mathrm{C}$. However, it also appears that extra cracks were then created after the oxide solidified but while the coating was still cooling. These were not sealed with oxide.

It may be noticed that the measured peak temperature $(1500 \pm 100){ }^{\circ} \mathrm{C}$ was less than the melting point of pure $\mathrm{SiO}_{2}\left(1723^{\circ} \mathrm{C}\right)[14]$ but the melting point of the extra oxide may have been lowered [15] because of the migration of some $\mathrm{Na}$ from the sodium silicate [9]. 10wt\% of sodium silicate would have been sufficient for the oxide to melt at $1500{ }^{\circ} \mathrm{C}$ [15]. The lack of $\mathrm{Na}$ in the extra oxide (e.g. in the crack of Fig. $7 \mathrm{~b}$ and surface of Fig 9b) was a consequence of dilution (the amount of oxide had increased by x2.5), vaporisation [9] and further migration of Na. This may have left a thin Na rich layer on the surface that could not be distinguished in cross-section. The sodium silicate was added, in part, to prevent oxidation of the $\mathrm{C} / \mathrm{C}$ by sealing the cracks [9]. However, in the regions studied the cracks were sealed by new Na poor oxide rather than sodium silicate.

Oxidation of the $\mathrm{C} / \mathrm{C}$ may also have produced carbon dioxide but no consumption of carbon was identified.

\subsection{Diffraction Results}

The diffraction results are presented in Figures 11 to 14 . Figure 11 is a conventional linear diffraction pattern, but Figures 12 to 14 contain details that require explanation. They show the phase concentration (Fig. 12) and strain (Figs. 13 and 14) as a function of depth. Beneath these depth distributions are backscattered electron images of the cross-sections to enable the variations in phase or strain to be linked to the variations in microstructure with depth. The images are labelled as in the microstructure section. These figures also include a bar indicating the thickness of the X-ray beam in the depth direction (X-ray beam size). This bar 
shows the range of depth that was averaged over to produce each data point. Figures 13 and 14 also contain $\mathrm{x}$ and $\mathrm{y}$ axis that enable the cross-sections to be related to orientations of the X-ray apparatus shown in Figures 2 and 3.

Zero on the plots depth scale was defined as the first X-ray diffraction pattern, this occurred when the bottom of the X-ray beam touched the top of the sample. The images are therefore displaced with respect to the depth scale by $0.05 \mathrm{~mm}$ for Figures 12 and 13 , and $0.025 \mathrm{~mm}$ for Figure 14 (half the thickness of the X-ray beam). Good strain data could not be derived from the pristine sample at zero depth hence Figure 13 has no data point there.

\subsubsection{Phase Mapping}

To identify the phases present and to map their concentrations with depth, diffraction patterns were obtained by integrating from 0 to $360^{\circ}$ in $\psi$ (around the diffraction rings) and converting the radius to Bragg angle. An example of such a linear diffraction pattern is shown in Figure 11.

The major phases were identified by comparing these diffraction patterns to those available from the Crystallography Open Database [16] (COD) using the identification program EVA [17] on patterns after linearization by FIT2d. The major phases were cristobalite, COD $9008110\left(\mathrm{SiO}_{2}\right)$, moissanite, COD $9010158(\mathrm{SiC})$ and graphite - 2H, COD 1200017 (C). It should be noted that the surface $\mathrm{SiO}_{2}$ layer was a sodium silicate glass [9] which, being amorphous, would not have produced a diffraction pattern. Like Figure 11 the diffraction patterns away from the $\mathrm{C} / \mathrm{C}$ also show large backgrounds between their diffraction peaks due to scattering from amorphous material. In comparison, the diffraction patterns from the ceria standard had low backgrounds as this standard contained no amorphous material. The crystalline cristobalite detected was therefore a minor phase; however, it was still a useful 
indicator of strain and the depth distribution of the silicon oxide material. Furthermore, although cristobalite is the high temperature crystalline phase of $\mathrm{SiO}_{2}$ it is metastable at room temperature.

A Rietveld or least squares fitting routine (TOPAS [18]) was used to determine the weight percentage of these different phases for each diffraction pattern and therefore at each depth. However, these calculated weight percentages do not take account of the significant amount of amorphous glass and can only be used as a guide for the depth distributions of the detected crystalline phases. The resultant depth profiles of these weight percentages are shown in Figure 12. It should be noted that the solid lines fitted to the data points are a visual guide and do not represent the predictions of a model. The error bars from the fits are shown unless they were smaller than the data point markers.

The variation of these phases was consistent with the SEM images and the EDS spectra. The concentration of silicon dioxide $\left(\mathrm{SiO}_{2}\right)$ was highest at a depth of $0 \mathrm{~mm}$ and fell rapidly over the first $0.1 \mathrm{~mm}$. Because of the $0.1 \mathrm{~mm}$ depth resolution (X-ray Beam Size in Fig. 12) the $\mathrm{SiO}_{2}$ signal over this $0.1 \mathrm{~mm}$ could have all been due to the $0.02 \mathrm{~mm}$ thick surface layer (Fig. 9a). However, the O EDS depth profile (Fig. 10a) suggests there was $\mathrm{SiO}_{2}$ throughout the $\mathrm{SiC}$ layer. The width of the change from $\mathrm{SiC}$ to graphite over $0.4 \mathrm{~mm}$ could not have been solely due to the $0.1 \mathrm{~mm}$ depth resolution. The $\mathrm{SiC}$ must have penetrated up to $0.35 \mathrm{~mm}$ beneath the surface. This is consistent with the SEM and EDS evidence (Figs. 7a, 8a, 10a and 12) of Si within the $\mathrm{C} / \mathrm{C}$. Combining the phase plot with the backscattered image suggests that the sample had a $0.1-0.15 \mathrm{~mm}$ thick layer of $\mathrm{SiC}$ ( $\mathrm{SiC}$ in Fig. 12), over a $0.1 \mathrm{~mm}$ thick transition region of graphite fibres in a $\mathrm{SiC}$ matrix ( $\mathrm{C} / \mathrm{SiC}$ in Fig. 12$)$, with some $\mathrm{SiC}$ penetrating up to $0.4 \mathrm{~mm}$ below the surface, followed by the carbon-carbon bulk (C/C in Fig. 12). 
It should be noted that although the concentration of the $\mathrm{SiO}_{2}$ below a depth $0.1 \mathrm{~mm}$ was small, its diffraction peaks were visible to the deeper edge of the transition region $(0.2-0.25$ $\mathrm{mm}$ ). Again this penetration was too large to be explained by the $0.1 \mathrm{~mm}$ depth resolution and was therefore real.

\subsubsection{Strain Mapping}

Differentiation of the Bragg Equation suggests that the diffraction lines at the higher Bragg angles would give the greatest sensitivity to strain. However, these lines are also weaker. Furthermore, several of the diffraction lines, including the strongest from the SiC phase, could not be used because interference from neighbouring lines shifted the centroids. The degree of interference also varied with depth. The choice of diffraction line was therefore a compromise between these competing factors. The strain results presented here were from two lines, the innermost cristobalite line $\left(\mathrm{d}=4.073 \AA, \mathrm{SiO}_{2}\left(\begin{array}{lll}0 & 1 & 1\end{array}\right)\right.$ in Fig. 11), and the third silicon carbide line from the centre of the diffraction pattern $\left(d=1.542 \AA\right.$, $\mathrm{SiC}\left(\begin{array}{lll}1 & 1 & 0\end{array}\right)$ in Fig. 11). In this strain results section these two lines are taken as representing the strains in the silicon oxides and the silicon carbide respectively and are referred to as $\mathrm{SiO}_{2}$ and $\mathrm{SiC}$. In Figure 4 the $\mathrm{SiC}(110)$ line is labelled (a) and the $\mathrm{SiO}_{2}(011)$ line (b).

The diffraction lines from both the silicon carbide and oxide are narrow (Fig. 11) and continuous over the complete range of $\psi$ or around the whole diffraction ring (Fig. 4). However, the graphite diffraction lines are both broad (Fig. 11) and produce only partial diffraction rings (Fig. 4). Both narrow lines and continuous diffraction rings are required for the strain measurement techniques employed here. The centroids of broad lines cannot be determined as accurately as those of narrow lines and therefore broad lines provide less sensitive measurements of strain. Similarly, Equation 3 cannot be accurately fitted to 
incomplete diffraction rings. Therefore in this work only the strains in the silicon carbide and oxide were measured. Potential methods for measuring the carbon strains are considered in the discussion section.

Figure 13 shows the depth profiles of strain for the pristine material. The image of the crosssection below the plot enables a direct comparison between the strains and the microstructure at the different depths. In the transition region $(\mathrm{C} / \mathrm{SiC})$ and in the $\mathrm{C} / \mathrm{C}$ to a depth of $0.4 \mathrm{~mm}$ the overall y-direction strain in the $\mathrm{SiC}$ phase was tensile $\left(4 \times 10^{-4}\right)$, but in the coating $(\mathrm{SiC})$ this strain was effectively zero. The overall y-direction strain in the $\mathrm{SiO}_{2}$ was also tensile $\left(5.5 \times 10^{-}\right.$ $\left.{ }^{4}\right)$. At depths greater than $0.1 \mathrm{~mm}$ the $\mathrm{SiO}_{2}(011)$ diffraction ring was not strong enough for the strain to be measured.

The $\mathrm{SiC}$ strain error bars were larger in the $\mathrm{SiC}$ layer and in the $\mathrm{C} / \mathrm{C}$ than in the $\mathrm{C} / \mathrm{SiC}$ layer (Fig. 13). In the SiC layer the large errors bars were caused by an increase in SiC crystallite size. This is compatible with Figure 9a which shows large $\mathrm{SiC}$ grains at the surface. This resulted in speckled diffraction lines biased by large diffraction spots rather than the smooth lines built-up from numerous indistinguishable diffraction spots from the $\mathrm{C} / \mathrm{SiC}$ layer. In the $\mathrm{C} / \mathrm{C}$, the larger SiC error bars were caused by poor statistics, which were in turn due to the low concentration of $\mathrm{SiC}$ at these depths. The errors in the $\mathrm{SiO}_{2}$ strain were also substantial. These were due to interference from neighbouring lines, a lower diffraction angle (which reduces sensitivity to strain), and a broader and less intense diffraction line. The effect of large crystallite size was less pronounced than for the shallow $\mathrm{SiC}$ material.

Figure 14 shows the strain measurements from the burnt region of the strip exposed to the flame of the oxy-acetylene torch. The strains in the $\mathrm{SiO}_{2}$ and the $\mathrm{SiC}$ are similar in polarity and magnitude to those of the pristine sample (Fig. 13). However, the diffraction signal from 
$\mathrm{SiO}_{2}$ remained strong to a depth of $0.25 \mathrm{~mm}$ and the strain in this phase rose in the $\mathrm{C} / \mathrm{SiC}$ transition region to reach a large tensile y-direction strain of $2.2 \times 10^{-3}$. The increased depth of the $\mathrm{SiO}_{2}$ diffraction signal was compatible with the SEM and EDS evidence (Figs. 7b and 10b). The deeper $\mathrm{SiO}_{2}$ could have been caused by oxidation or the inward flow of the molten $\mathrm{SiO}_{2}$ on the surface. Figure 14 also shows that, in contrast to the pristine strip (Fig. 13), the strain in the SiC decreased below $0.25 \mathrm{~mm}$.

The depth profile of strain from the rear of the heated sample was closer in appearance to that of the pristine sample with no fall off of the strain in the $\mathrm{SiC}$ at depth. Similarly, reliable strain measurements could only be obtained from the $\mathrm{SiO}_{2}$ close to the surface. The similarly between the strain depth profiles from the pristine and the rear of the heated sample were explicable as the rear of the heated sample showed no evidence of oxidation or pinholes. Heating from the oxy-acetylene flame was localised to the front surface.

\section{Discussion}

Figure 15 shows a schematic diagram of the material in cross-section that summarises the strain mapping results for the pristine case. The polarity (tensile or compressive) of the observed $\mathrm{SiC}$ strains are compatible with the reported coating process where the $\mathrm{SiC}$ was formed at $\sim 1650^{\circ} \mathrm{C}[9]$ and shrank more than the carbon substrate as it cooled. This cooling strain mechanism would have created the observed in-plane tension in the $\mathrm{C} / \mathrm{SiC}$ region for the pristine case. It was expected that this mechanism would have also created a balancing compression in the underlying $\mathrm{C} / \mathrm{C}$. The direction of this compressive strain would have been parallel to the tension in the coating. Similarly the direction of the observed $\mathrm{SiO}_{2}$ tensile strains are compatible with an $\mathrm{SiO}_{2}$ layer deposited onto the $\mathrm{SiC}$ coating at an elevated temperature (not reported) which then shrank more than its $\mathrm{SiC}$ substrate on cooling to room 
temperature. Again this mechanism would have created a balancing compressive strain this time in the underlying $\mathrm{SiC}$.

The through-thickness cracks observed in bulk of the SiC layer were likely to have formed during cooling because the tensile stresses created in the plane of the layer on cooling were greater than the tensile strength of the SiC. This cracking partly explains the measured low strain in the $\mathrm{SiC}$ layer (region $\mathrm{SiC}$ in Fig. 13); as the through-thickness cracks relaxed the tensile cooling strain. The tensile strain in the SiC layer was also reduced by the balancing compressive strain from the $\mathrm{SiO}_{2}$ layer. However, as most of these cracks did not penetrate into the $\mathrm{C} / \mathrm{C}$ the $\mathrm{SiC}$ just above the $\mathrm{C} / \mathrm{C}$ was in tension. The cracking did not relax the strains in the $\mathrm{SiO}_{2}$ layer because the layer's thickness $(0.02 \mathrm{~mm})$ was much less than the crack spacing (1.6mm pristine case).

In the heated material the overall CTE of the coating increased as the oxides inside the coating solidified. This led to greater strains than in the pristine case. Furthermore, with a lower concentration of $\mathrm{Na}$ (section 3.1.2) the oxides solidified at higher temperatures, further increasing the cooling strain because of the larger temperature drop. This can be seen from the increase in the maximum in-plane tensile strain in the $\mathrm{SiO}_{2}$ which changed from 0.00075 (Fig. 13) to 0.00225 (Fig. 14). The larger tensile strain then caused the greater density of throughthickness cracks. After heating the increase and spread of the $\mathrm{SiO}_{2}$ simplified the structure into two zones: a coating that was in tension and a substrate that was in compression.

Overall the strain measurements confirm previous work that CTE mismatch between the SiC coating and the $\mathrm{C} / \mathrm{C}$ substrate leads to through-thickness cracking which will limit the degree of oxidation resistance provided by the coating [2]. However, although the observed patterns of strains were compatible with previous reports $[2,9]$ the magnitudes of the strains were 
lower than expected. The magnitudes of the cooling strains expected for layers $\left(\varepsilon_{l}\right)$ with a single constituent (i.e. pure glass, on pure $\mathrm{SiC}$, on pure $\mathrm{C} / \mathrm{C}$ ) can be easily calculated using Equation 4. This equation relies on the assumption that the thin layer conforms to the thicker and stiffer substrate on cooling, and the final substrate dimensions are unaffected by the layer.

$$
\varepsilon_{1}=\Delta \mathrm{T}\left(\alpha_{1}-\alpha_{\mathrm{s}}\right)
$$

The coefficients of thermal expansion (CTE) of the layer $\left(\alpha_{1}\right)$ and its substrate $\left(\alpha_{\mathrm{s}}\right)$ and the associated temperature drops $(\Delta \mathrm{T})$ were obtained from the literature and are listed in Table 1. Table 1 also compares the calculated and the maximum measured values of the strains. The calculated magnitudes for the $\mathrm{SiC}$ and the sodium silicate were 14 and 7 times greater than the corresponding maximum measured magnitudes for the $\mathrm{SiC}$ and $\mathrm{SiO}_{2}$.

If the mechanisms responsible for reducing strain in the $\mathrm{SiC}$ and $\mathrm{SiO}_{2}$ are identified it may become possible to utilise them to further reduce strain. This would then decrease the density of through-thicknesses cracking and thereby improve oxidation resistance. Obviously, the mechanism of reducing strain by through-thickness cracking is not considered because it decreases oxidation protection. Three other mechanisms were proposed to account for the low measured strains:

1. Weak interfaces between different components that only partially transfer mechanical loads.

2. A reduction in the CTE difference between the layer and substrate because of the mixing of the layer and substrate components.

3. The $\mathrm{C} / \mathrm{C}$ adjacent to the coating was substantially compressed by the coating as it contracted (Eq. 4 invalid). 
Mechanism 1: The strain in the isolated ribbons of $\mathrm{SiC}$ and $\mathrm{SiO}_{2}$ within the $\mathrm{C} / \mathrm{C}$ may have been reduced by having weak interfaces with the surrounding $\mathrm{C} / \mathrm{C}$. Figure 8 indicates that they partially occupied pores and microcracks in the $\mathrm{C} / \mathrm{C}$ and that some have free surfaces. This lack of constraint explains the moderate levels of strain achieved in the $\mathrm{SiO}_{2}$ and $\mathrm{SiC}$ within the $\mathrm{C} / \mathrm{C}$ (Figs. 13 and 14 below 0.25 and $0.2 \mathrm{~mm}$ respectively). However, it does not appear that this mechanism reduced the strains in the $\mathrm{SiC}$ layer.

Mechanism 2: The $\mathrm{C} / \mathrm{C}$ adjacent to the $\mathrm{C} / \mathrm{SiC}$ layer also contained $\mathrm{SiC}$ and $\mathrm{SiO}_{2}$ and would therefore have had a CTE closer to the coating than the pure C/C. As Equation 4 indicates this would reduce the strain in the $\mathrm{SiC}$ layer.

Mechanism 3: The amount by which the $\mathrm{C} / \mathrm{C}$ can be compressed, and the tensile strain in the coating reduced, is related to the ratio of the elastic moduli of the coating ( $\mathrm{SiC} 410 \mathrm{GPa}$ [21] and glass 74-65 GPa [21]) and the C/C (in-plane compression $69 \mathrm{GPa}$ [22]) as well as their relative thicknesses. Although the $\mathrm{C} / \mathrm{C}$ is thick its elastic modulus is less than that of the coating components. The elastic modulus of the $\mathrm{C} / \mathrm{C}$ is larger in tension (110-125 GPa [23]) but in compression the fibres can bow and eventually buckle [22]. Therefore mechanism 3 would have reduced the strain in $\mathrm{SiC}$ layer.

To extend mechanism 3 to achieve even lower strains the compressive elastic modulus of the $\mathrm{C} / \mathrm{C}$ could be reduced by decreasing the fibre density. However, for structural applications the $\mathrm{C} / \mathrm{C}$ is required to be rigid. An alternative is a low elastic modulus buffer layer between the coating and the $\mathrm{C} / \mathrm{C}$. Its upper layers would conform to the expansion and contraction of the coating, while its lower layers would conform to the $\mathrm{C} / \mathrm{C}$. A candidate material for this buffer layer is the graphite that forms the $\mathrm{C} / \mathrm{C}$ matrix. Its $\mathrm{CTE}$ has already proved to be compatible 
with the $\mathrm{C} / \mathrm{C}$. A reasonable estimate of its modulus is the modulus of the $2 \mathrm{D} \mathrm{C} / \mathrm{C}$ perpendicular to the fibre plane, which is a low $4.1 \mathrm{GPa}$ [23]. It is estimated that the strain in the coating will reduce by a factor of 17 (the ratio of the in-plane $\mathrm{C} / \mathrm{C}$ modulus and that of the buffer layer graphite). The buffer layer could be created by adding layers of phenolic resin on to the $\mathrm{C} / \mathrm{C}$ and transforming them to graphite by pyrolysis. The conversion coating process would then be used to convert the outer layer of graphite to SiC. A schematic of this proposed design is shown in Figure 16.

To extend mechanism 2 to achieve even lower strains short $\mathrm{SiC}$ fibres could also be added to the outer layers of resin to grade the buffer layer from graphite (C) to graphite plus SiC fibres $(\mathrm{C} / \mathrm{SiC})$. The conversion coating process would then create a ceramic matrix composite of $\mathrm{SiC}$ fibres in a $\mathrm{SiC}$ matrix $(\mathrm{SiC} / \mathrm{SiC})$. The toughness of the ceramic matrix composite formed may further reduce the amount of through thickness cracks [24]. The SiC fibres still within graphite would further reduce strains by grading the change in CTE.

If the strain is reduced sufficiently to prevent the formation of through thickness cracks the layer of sodium silicate will not be necessary to seal the cracks. This would make the oxidation protection system more durable as the sodium silicate would not need to be replaced because of the loss of sodium during heating [2].

The results of this work demonstrate the need for future investigations, in particular the development of finite element models, the development of techniques to measure the strain in the carbon, and the measurement of the coating strains during heating. The development of finite element models of the microstructures based on the SEM images or micro-CT could be used to calculate more realistic strain distributions for comparison with the measured values, and to predict how these distributions would change with thermal cycling and oxidation. They 
could also be used to explore the effects of the proposed buffer layer on the strain distributions. Alternative coatings based on ultra-high temperature ceramics [3] are also likely to suffer from through-thickness cracking where the CTE mismatch is greater than that for $\mathrm{SiC}$ (e.g. $\mathrm{HfB}_{2}$ and $\mathrm{HfC}$ [2]). A graphite buffer layer may also prove useful for these alternative coatings. The development of techniques for measuring the strain in the $\mathrm{C} / \mathrm{C}$ that take into account the breadth of the diffraction lines, their asymmetry [12] and the periodic texture of the composite should be possible. X-ray diffraction has been successfully employed to measure strains in carbon fibre composites [25]. Calibrating the small shifts in the graphite diffraction peaks by applying known loads in-situ will help test the techniques. Strain mapping of these coatings at a range of temperatures will show how the strains vary once the glass become soft and fluid and how the loss of sodium will change this. It will also show if any phases go into compression at high temperatures $\left(1650^{\circ} \mathrm{C}\right)$. This can occur when the molar volume of a newly created phase is greater than that phase it replaces. This could have happened during the internal oxidation of the $\mathrm{SiC}$ coating and during the formation of the $\mathrm{SiC}$ by reaction of $\mathrm{Si}$ with $\mathrm{C}$. Some relevant molar volumes are listed in Table 1.

\section{Conclusions}

High energy X-ray diffraction was successful in providing phase and strain information as a function of depth through a protective $0.2 \mathrm{~mm}$ thick coating on $\mathrm{C} / \mathrm{C}$. It was concluded that the moderate elastic modulus of the $\mathrm{C} / \mathrm{C}$ in compression and the graded composition of the coating to $\mathrm{C} / \mathrm{C}$ interface reduced the strains in the $\mathrm{SiC}$ just above the $\mathrm{C} / \mathrm{C}$ to a factor of $1 / 14$ of the predicted value. The results suggested that oxidation resistance could be improved by reducing the tensile strain and consequently reducing the density of through-thickness cracks. It was proposed that this could be accomplished by introducing a buffer layer of graphite between the $\mathrm{C} / \mathrm{C}$ and the $\mathrm{SiC}$ that was graded in composition. 


\section{Acknowledgements}

The authors would like to thank Matthew Zonneveldt of DSTO for his help in preparing the samples. This research was supported by the science and industry endowment fund. CHESS is supported by the NSF and NIH/NIGMS via NSF award DMR-0936384. The C/C material was manufactured by CCAT and supplied by AFRL under the HiFIRE international collaborative program. 


\section{References}

[1] R. Wei $\beta$, Carbon/Carbons and Their Industrial Applications, in Ceramic Matrix Composites, edited by W. Krenkel (2008) Wiley, p. 69-109.

[2] J. E. Sheehan, Oxidation Protection for Carbon Fiber Composites, Carbon, 27 (1989) 709 715 .

[3] E. L. Corral, R.E. Loehman, Ultra-High Temperature Ceramic Coatings for Oxidation Protection of Carbon-Carbon Composites, J. Am. Ceram. Soc. 91[5] (2008) 1495-1502.

[4] R.D. Veltri, F.S. Galasso, Composite Silicon Carbide Coatings for Carbon-Carbon Materials, U.S. Patent 4,476,178 (1984).

[5] R.T. Bhatt, T.R. McCue, J.A. DiCarlo, Thermal stability of melt infiltrated SiC/SiC composites, Ceramic Eng. and Sci. Proceedings, 24 (2003) 295-300.

[6] J.R. Strife, J.E. Sheehan, Ceramic Coatings for Carbon-Carbon, Ceramic Bulletin, 67 (1988) 369-374.

[7] J. Thornton, S. Slater, J. Almer, The Measurement of Residual Strains Within Thermal Barrier Coatings Using High-Energy X-ray Diffraction, J. Am. Ceram. Soc. 88 [10] (2005) 2817-2825.

[8] B.J. Harder, J.D. Almer, C.M. Weyant, K.N. Lee and K.T. Faber, Residual Stress Analysis of Multilayer Environmental Barrier Coatings, J. Am. Ceram. Soc., 92 (2009) 452-459.

[9] N. Jacobson, D. Hull, J. Cawley, D. Curry, Kinetics and Mechanism of Oxidation of the Reinforced Carbon/Carbon on the Space Shuttle Orbiter, Advanced Ceramic Coatings and Interfaces V, (2010) pub. Am. Ceram. Soc., p. 3-21.

[10] A. Kazimov, D-M Smilgies, Q. Shen, X. Xiao, Q. Hao, E. Fontes, D.H. Bilderback, S.M. Gruner, Y.Platonov and V.V. Martynov, Multilayer X-ray optics at CHESS, J. Synchrotron Rad., 13 (2006) 204-210.

[11] National Institute of Standards and Technology, MD, USA, Standard Reference Material $674 b$ (2012) $\mathrm{CeO}_{2}$ fluorite structure.

[12] I.C. Noyan and J.B. Cohen, Residual Stress, Springer-Verlag New-York Inc. (1987) p. 166-186.

[13] A. P. Hammersley, European Synchrotron Research Facility (ESRF), Internal Report, ESRF98HA01T, FIT2D V9.129 Reference Manual V3.1 (1998) ESRF, Grenoble, France.

[14] J.F. Shackelford and W. Alexander, Materials Science and Engineering Handbook, $3^{\text {rd }}$ edition, pub. CRC Press (2001) Tables 149, 40, and 41.

[15] W.D. Kingery, H.K. Bowen, D.R. Uhlmann, Introduction to Ceramics, $2^{\text {nd }}$ edition (1976) John Wiley and Sons, p.288. 
[16] Grazulis, S., Chateigner, D., Downs, R. T., Yokochi, A. T., Quiros, M., Lutterotti, L., Manakova, E., Butkus, J., Moeck, P. \& Le Bail, A. (2009) "Crystallography Open Database an open-access collection of crystal structures". J. Appl. Cryst. 42, 726-729.

[17] EVA Phase Identification Software, ver. 2.0 (2011) Pubs Bruker AXS USA, www.bruker-axs.com.

[18] TOPAS Software for Rietveld Analysis of X-ray Diffraction Patterns, ver. 4.2 (2009) Pubs. Bruker AXS USA, www.bruker-axs.com.

[19] R. Asthana, A. Kumar, N.B. Dahote, Materials Processing and Manufacturing Science (2006) pubs. Butterworth and Heineman, p. 514.

[20] D.R. Lide, CRC Handbook of Chemistry and Physics, (1997-8) $78^{\text {th }}$ edition, CRC Press, p. 12-93 and 4-49.

[21] M.F. Ashby, D. R. H. Jones, Engineering Materials 2, Pergamon Press (1986) p150.

[22] J.A. Grape and V. Gupta, Failure Mechanisms in Laminated Carbon/Carbon Composites Under Biaxial Compression, Acta Matall. Mater., 43 (1995) 2657-2665.

[23] J.E. Sheehan, K.W. Buesking and B.J. Sullivan, Carbon-Carbon Composites, Annu. Rev. Mater. Sci. 24 (1994) 19-44

[24] J. Lamon, Interfaces and Interphases, in Ceramic Matrix Composites, ed. W. Krenkel (2008) Wiley, p. 69-109.

[25] T. Nishino, H. Naito, K. Nakamura, K. Nakamae, X-ray diffraction studies on the stress transfer of transversely loaded carbon fibre reinforced composite, Composites A31 (2000) 1225-1230. 


\section{Tables}

Table I Maximum measured (M.M.) strains compared to calculated cooling strains (cal. strain), and data from the literature relevant to strain. The Start Temp. were the starting temperatures for the cooling strain calculations and $25^{\circ} \mathrm{C}$ was the final temperature. It was assumed that SiC cooled from its formation temperature [9], cristobalite from the maximum temperature during heating (its melting point is $1713^{\circ} \mathrm{C}[15]$ ), and sodium silicate from its melting point (i.e. when it solidified).

\begin{tabular}{|c|c|c|c|c|c|}
\hline Phase & $\begin{array}{c}\text { CTE } \\
\left(\times 10^{-6} / \mathrm{C}^{-1}\right)\end{array}$ & $\begin{array}{l}\text { Molar Volume } \\
\left.\text { (x10-6 } \mathrm{m}^{3} / \mathrm{mol} .\right)\end{array}$ & $\begin{array}{l}\text { Start Temp. } \\
\qquad\left({ }^{\circ} \mathrm{C}\right)\end{array}$ & $\begin{array}{l}\text { Cal. Strain } \\
\left(\times 10^{-4}\right)\end{array}$ & $\begin{array}{c}\text { M.M. } \\
\text { Strain }\left(\times 10^{-4}\right)\end{array}$ \\
\hline $\mathrm{C} / \mathrm{C}$ & $1.1[6]$ & $\begin{array}{c}5.46 \text { (graphite) } \\
{[20]}\end{array}$ & & & \\
\hline $\mathrm{SiC}$ & $5.48[14]$ & 12.46 (hex.) [14] & $1650^{\circ} \mathrm{C}[9]$ & 71 & $5 \pm 0.5$ \\
\hline cristobalite & 10.3 [19] & $25.7[14]$ & 1500 & 135 (on $\mathrm{C} / \mathrm{C}$ ) & $\begin{array}{l}22.5 \pm 1.5 \\
\text { (heated) }\end{array}$ \\
\hline $\begin{array}{c}\mathrm{SiO}_{2} 20 \mathrm{~mol} \% \\
\mathrm{Na}_{2} \mathrm{O}\end{array}$ & 12 [14] & $26.3[14]$ & $800^{\circ} \mathrm{C}[15]$ & 50 (on $\mathrm{SiC})$ & $\begin{array}{c}7.5 \pm 4 \\
\text { (pristine) }\end{array}$ \\
\hline $\mathrm{Si}$ & $2.49[20]$ & $12.07[20]$ & & & \\
\hline
\end{tabular}




\section{List of Figure Captions}

Figure 1 Optical image of the C/C plate in cross-section. Two of the carbon fibre bundles running across the page are labelled $b$.

Figure 2 Schematic diagrams of a $3 \times 3 \mathrm{~cm}$ C/C sample viewed from the top, and the side view of the strip cut from the sample after exposure to the flame. The cut lines are shown as dashes and the heat affected region as mid-tone grey. The axes enable the relationship with the X-ray beam and detector to be visualised when compared to Figure 3.

Figure 3 Schematic diagram of the experimental layout where the incident and transmitted $X$ ray beam is shown as a dotted line, the diffracted $X$-ray beams are shown as solid arrows, $S$ is the strip, $\theta$ is the Bragg angle, $L$ is the sample to detector distance, $E$ is the end stop for the $X$ ray beam, $D$ is the detector, $r$ is the radius of the diffraction ring, $\psi$ is the azimuthal angle around the diffraction ring. The directions $x, y$ and $z$ are defined here. The vertical direction was $x$. Diffraction rings are shown on the detector; a solid circle for the strain free material, and a dotted ellipse from material compressed in the y-direction.

Figure 4 An example of output from the area detector showing the diffraction rings and the shadow of the beam stop, where (a) is the SiC diffraction ring used for the strain mapping, (b) is the $\mathrm{SiO}_{2}$ diffraction ring used for the strain mapping, and (c) is the diffuse diffraction ring from the carbon fibres. The carbon ring consists of just two arcs because of the alignment of the carbon planes with the axis of the fibres.

Figure 5 Open circles show the measured d-spacing $\left(d_{\psi}\right)$ versus azimuthal angle $(\psi)$ for strained SiC (0.25mm below the surface). Closed squares show the fit to the data using 
Equation 3. Non-strained SiC would have a constant d-spacing as shown by the horizontal dashed line. An error bar (closed circles at ends) shows how the scatter in d-spacing would broaden this strain free line.

Figure 6 Backscattered electron images of the surface of the coating for the pristine (a) and heated (b) strips.

Figure 7 Backscattered electron images of the cross-sections of the pristine $(a)$ and heated $(b)$ strips.

Figure 8 Backscattered electron images of the cross-sections of the pristine (a) and heated $(b)$ strips within the C/C below the C/SiC layer.

Figure 9 Backscattered electron images of the cross-sections of the pristine (a) and heated (b) coated carbon-carbon showing the grains of SiC on the surface (SiC grains) and the matrix of oxide (oxide) that joins them.

Figure 10 Elemental depth profiles for Si, $C$ and $O$ given by EDS for the pristine (a) and heated material (b).

Figure 11 Linear $X$-ray diffraction pattern from the transition region $0.25 \mathrm{~mm}$ below the surface. The major diffraction lines are labelled with the compound and the Miller index of the corresponding set of lattice planes.

Figure 12 Concentrations of the three phases: cristobalite ( $\mathrm{SiO}_{2}$ and open circles), moissanite (SiC and closed squares) and graphite-2H (C and open triangles) as a function of depth as 
determined from the integrated diffraction patterns. Cross-section included for comparison with microstructure.

Figure 13 Strains in the cristobalite ( $\mathrm{SiO}_{2}$ and open symbols) and $\mathrm{SiC}$ (closed symbols) plotted as a function of depth for the pristine material. The solid lines fitted to the data points are a visual guide and do not represent the predictions of a model. Cross-section included for comparison with microstructure.

Figure 14 Strains in the cristobalite ( $\mathrm{SiO}_{2}$ and open symbols) and $\mathrm{SiC}$ (closed symbols) for the heated material. The solid lines fitted to the data points are a visual guide and do not represent the predictions of a model. Cross-section included for comparison with microstructure.

Figure 15 Schematic diagram of the coating cross-section showing the observed and inferred strains at the different depths for the pristine material. The strain in the $C / C$ is inferred. In this Figure ' $a$ ' is a through thickness crack in the coating and ' $b$ ' is the top layer of the coating which had a matrix of $\mathrm{SiO}_{2}$.

Figure 16 Schematic diagram of the proposed structure for reducing cooling strains in the coating. 
Figures

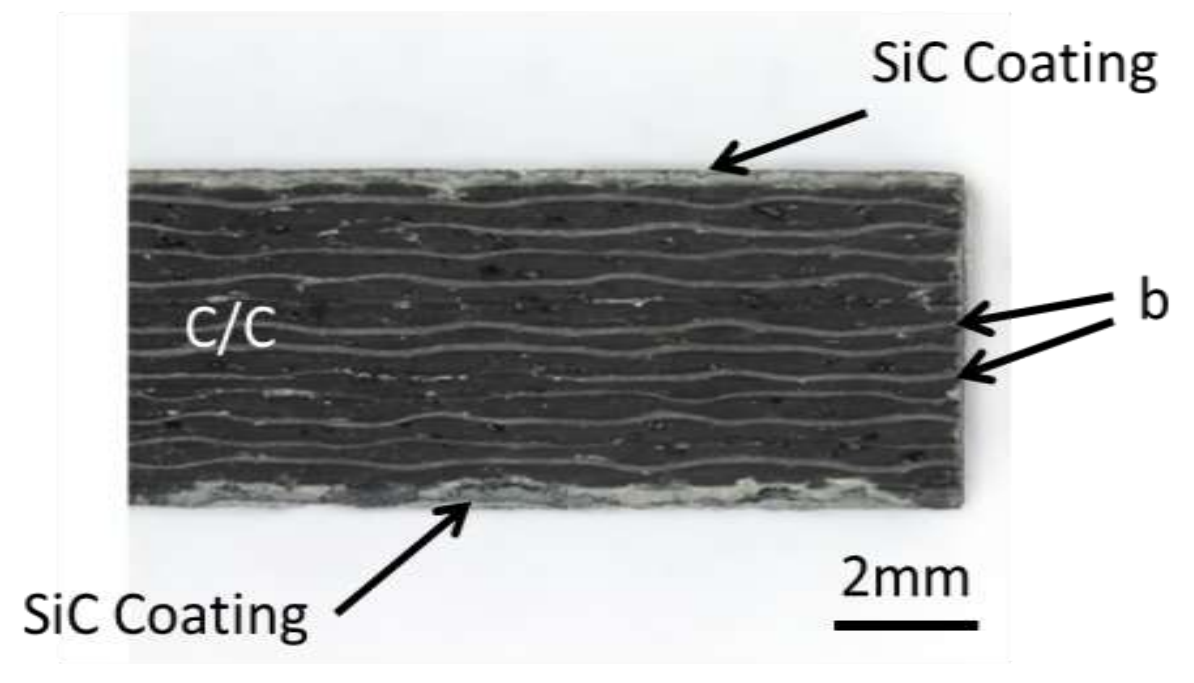

Fig. 1 


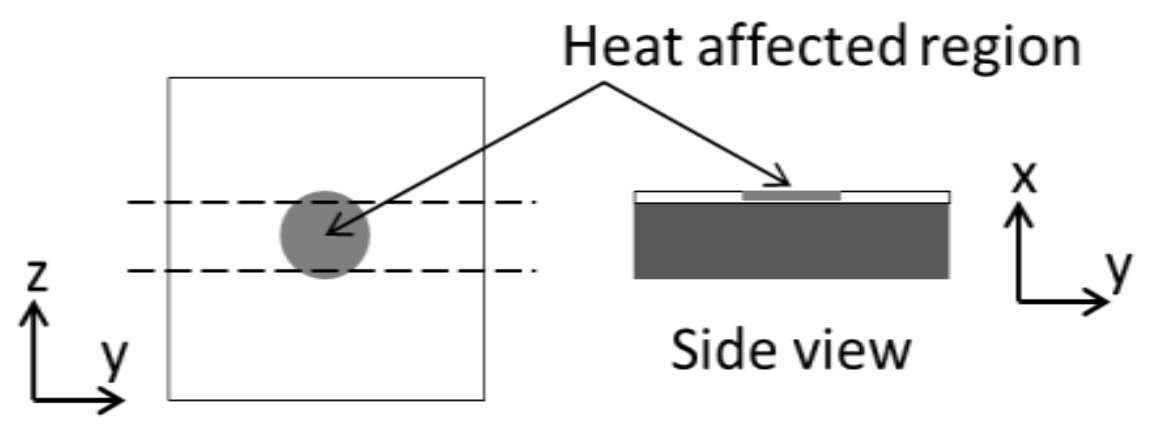

Top view

Fig. 2 


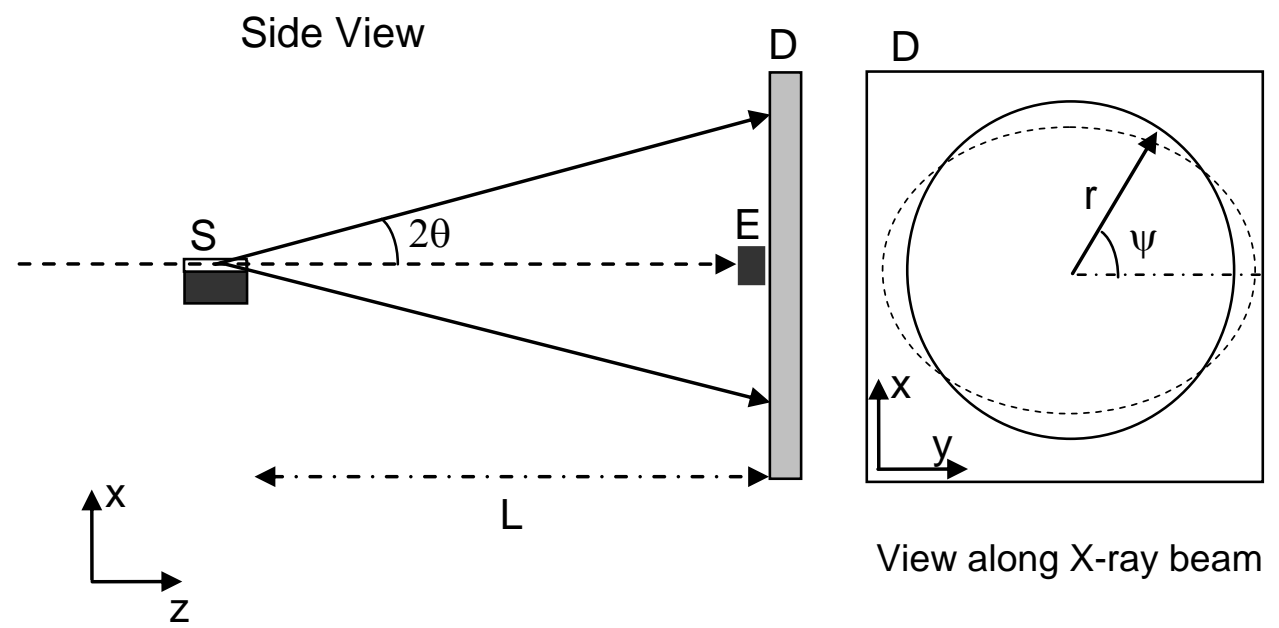

Fig. 3 


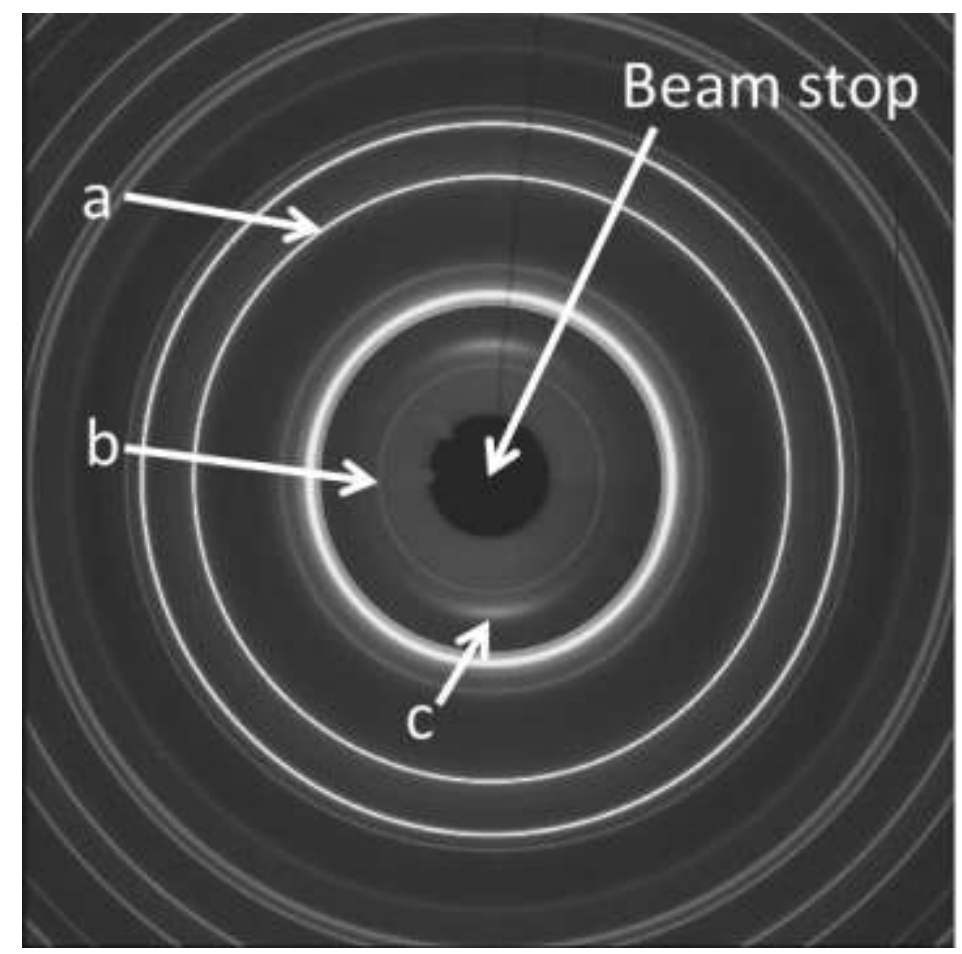

Fig. 4 


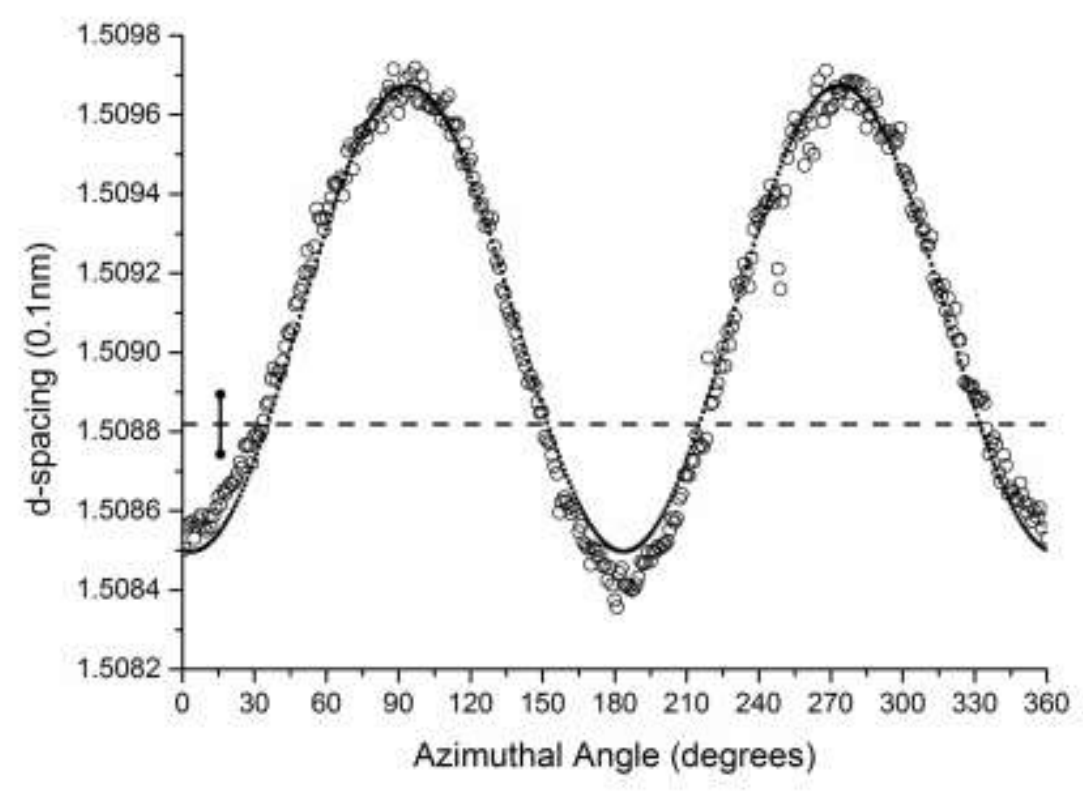

Fig. 5 

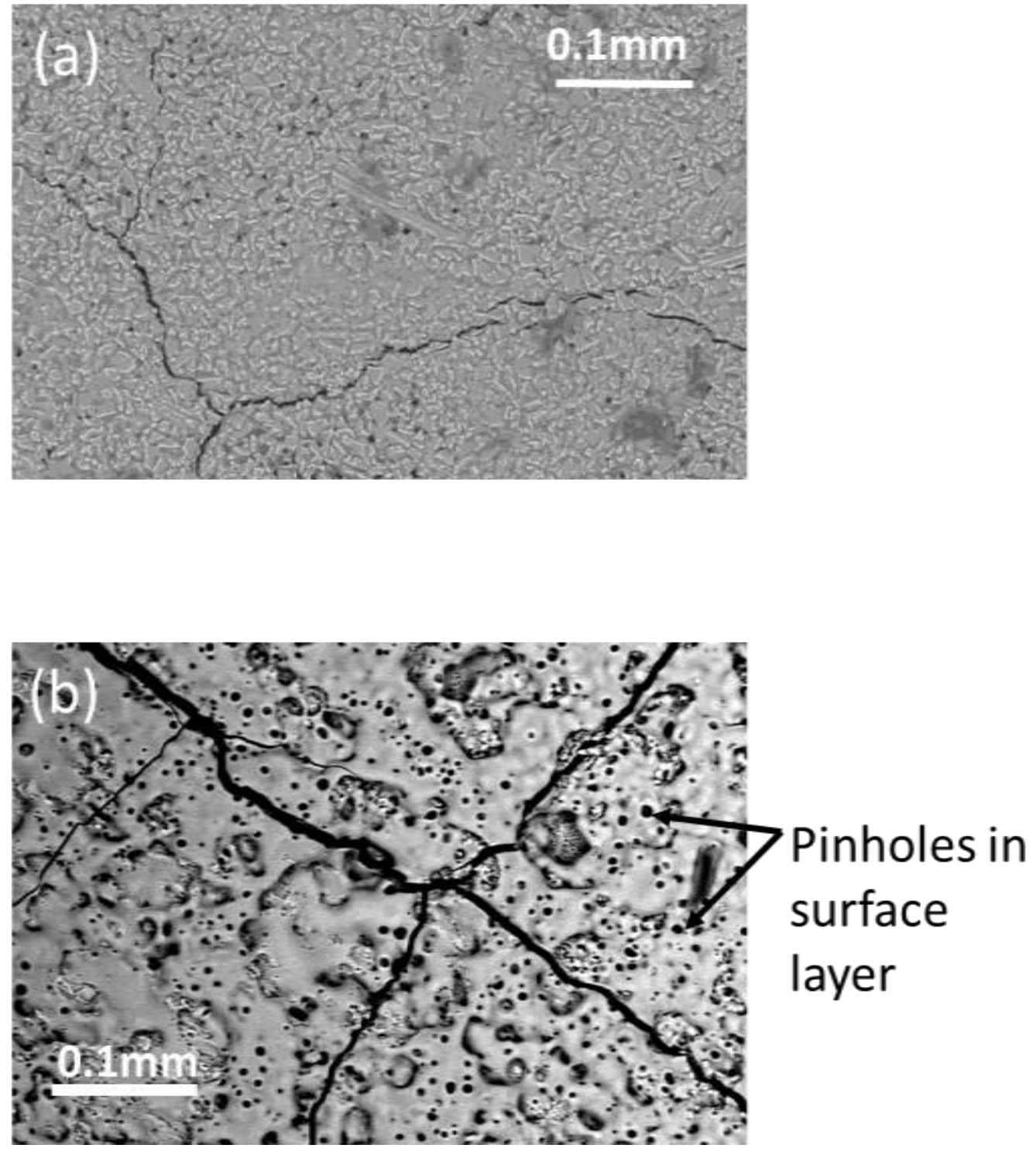

Fig. 6 

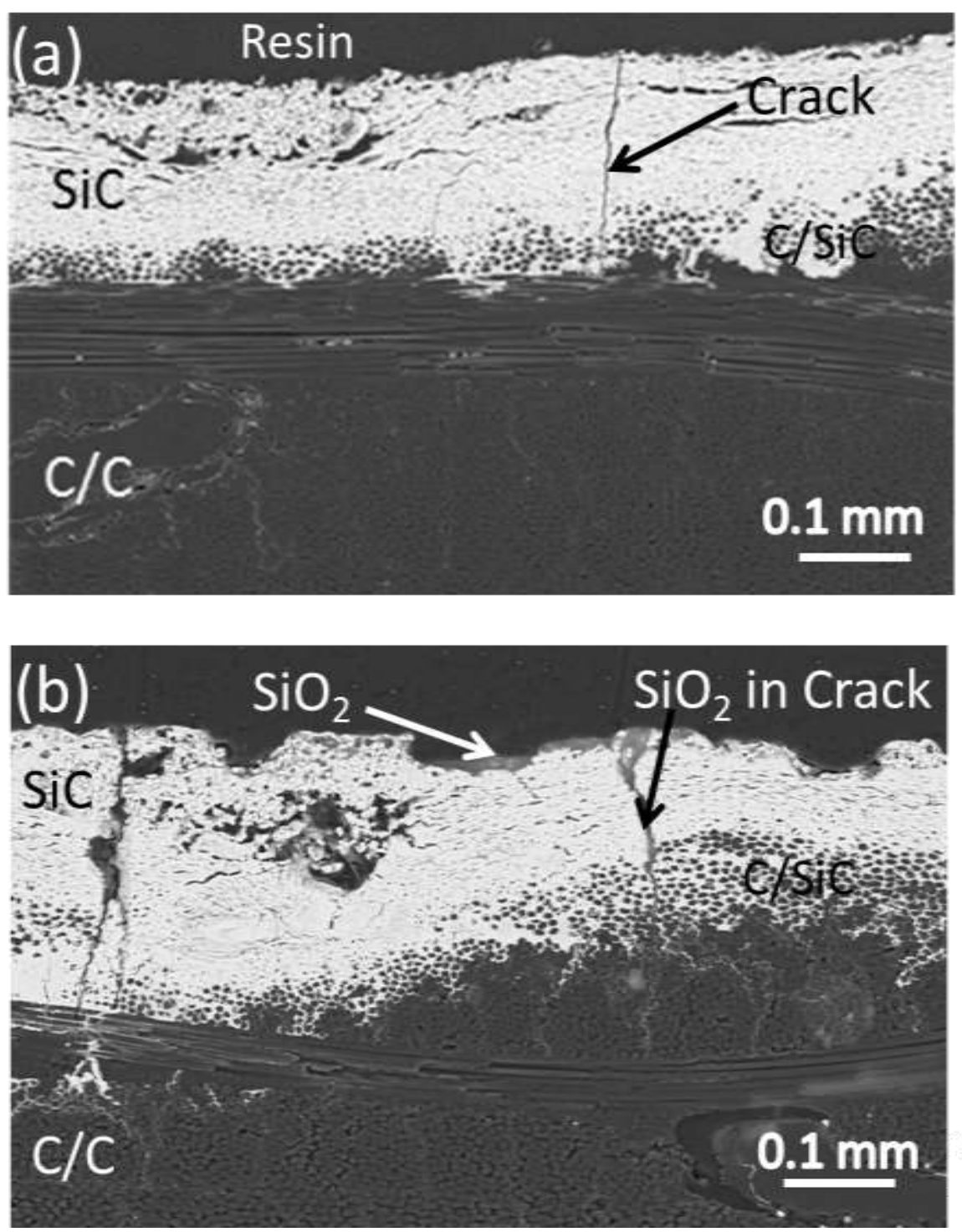

Fig. 7 

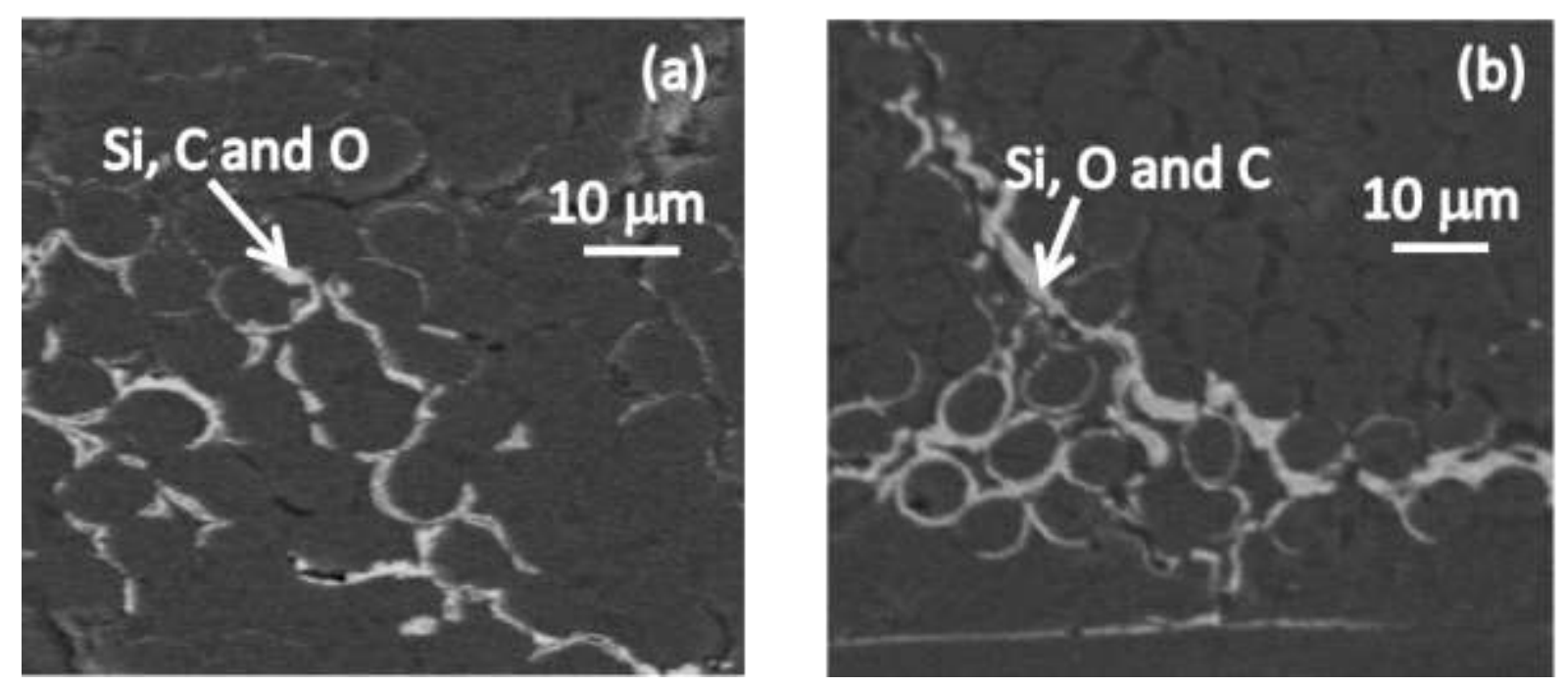

Fig. 8 

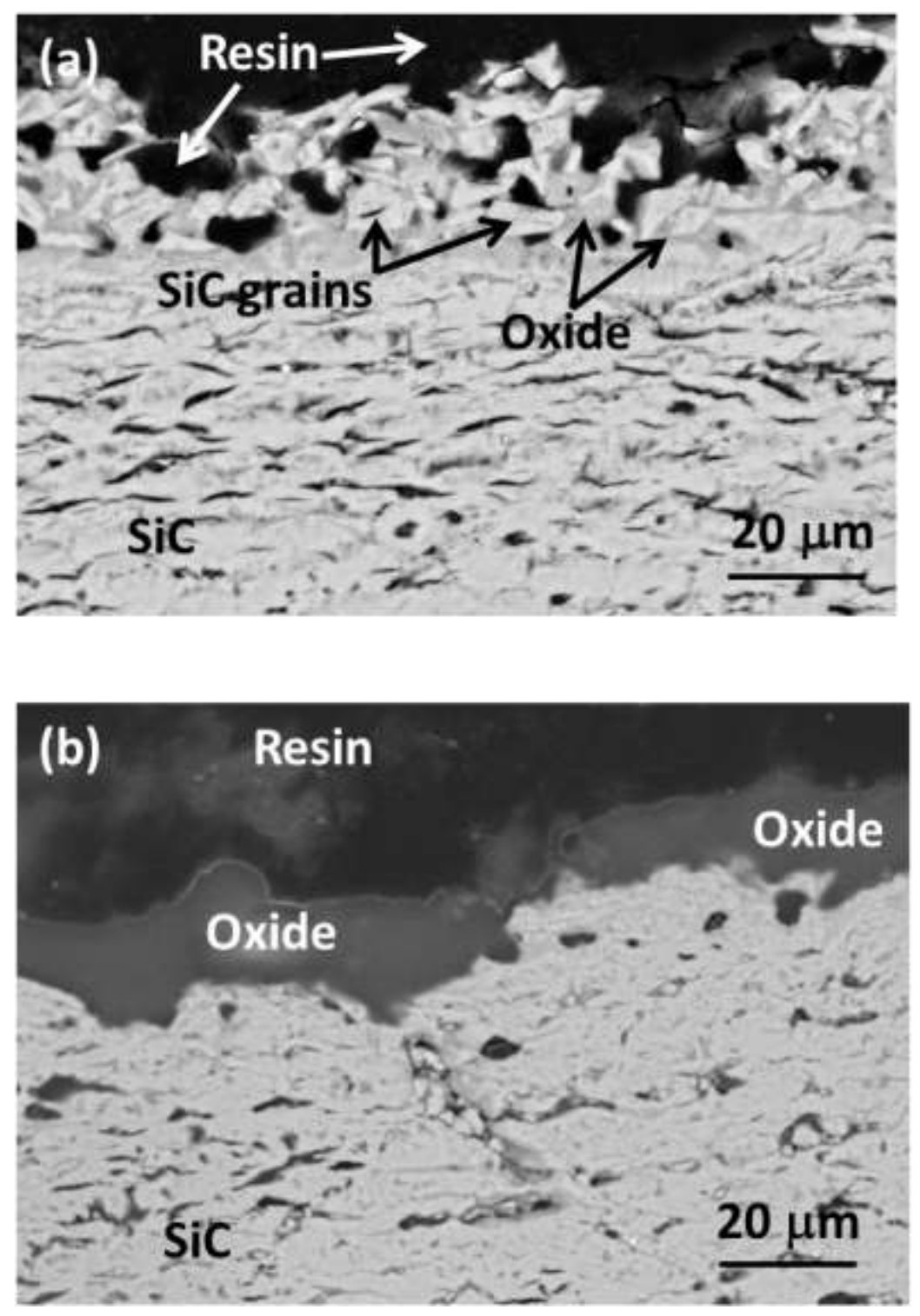

Fig. 9 

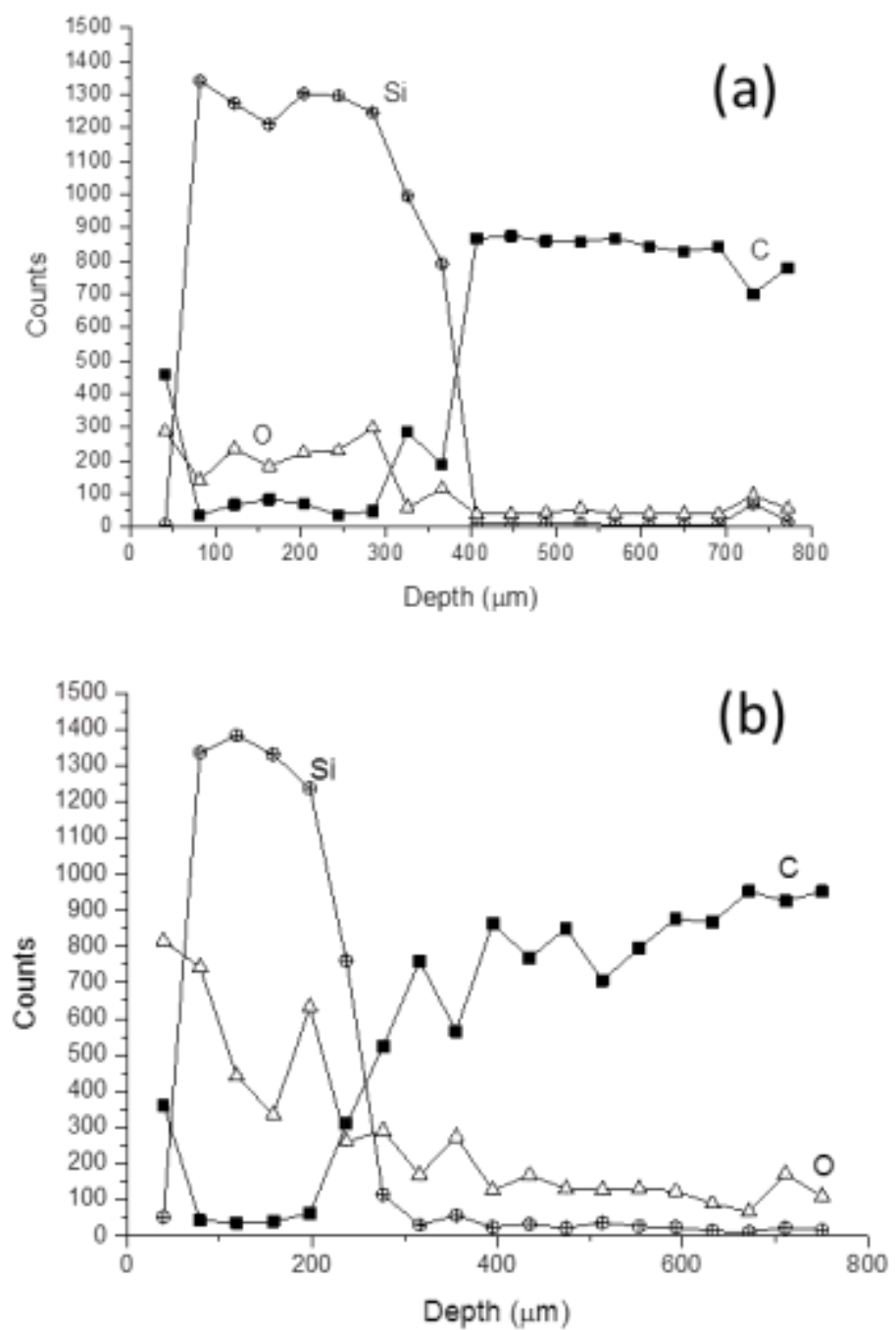

Fig. 10 


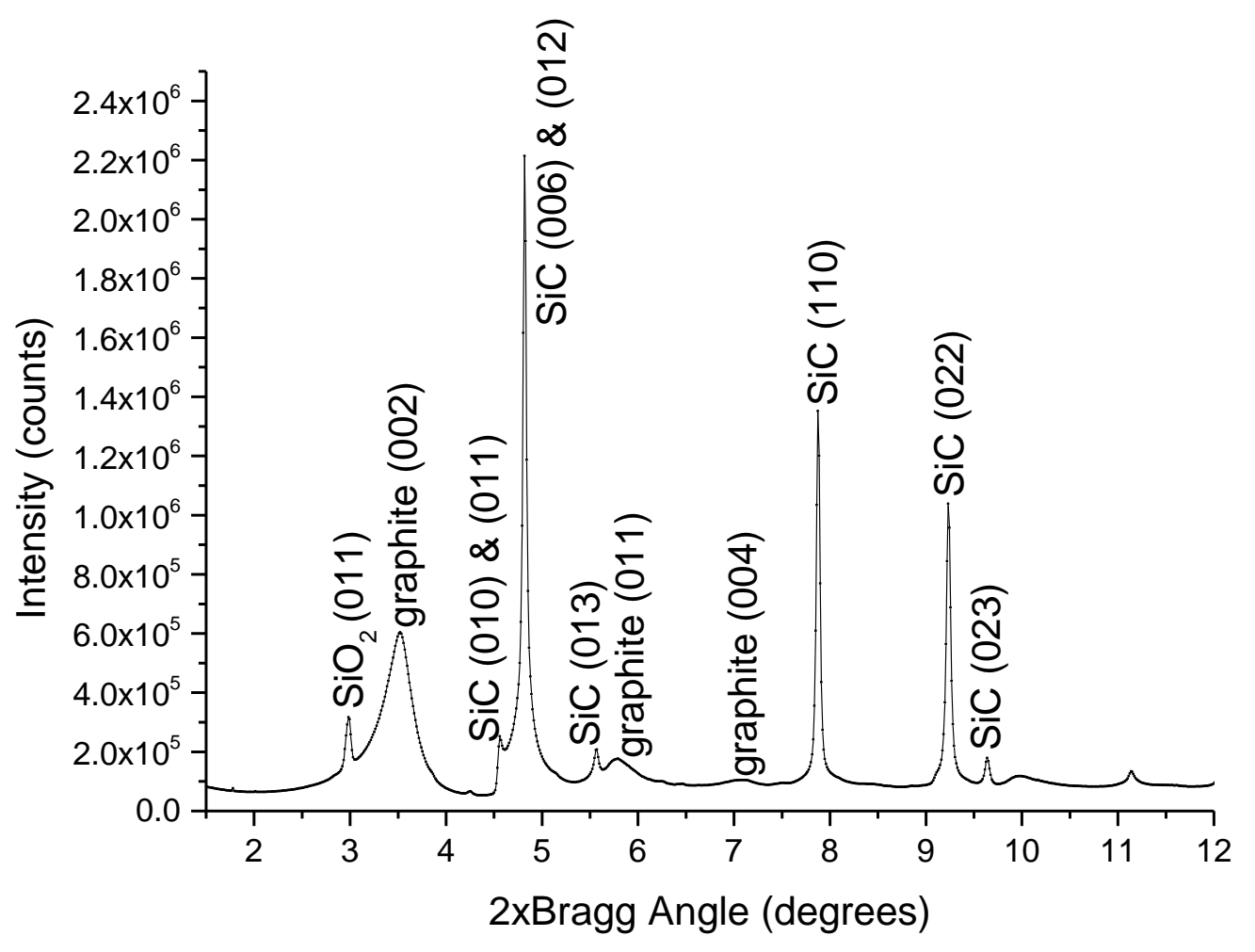

Fig. 11 

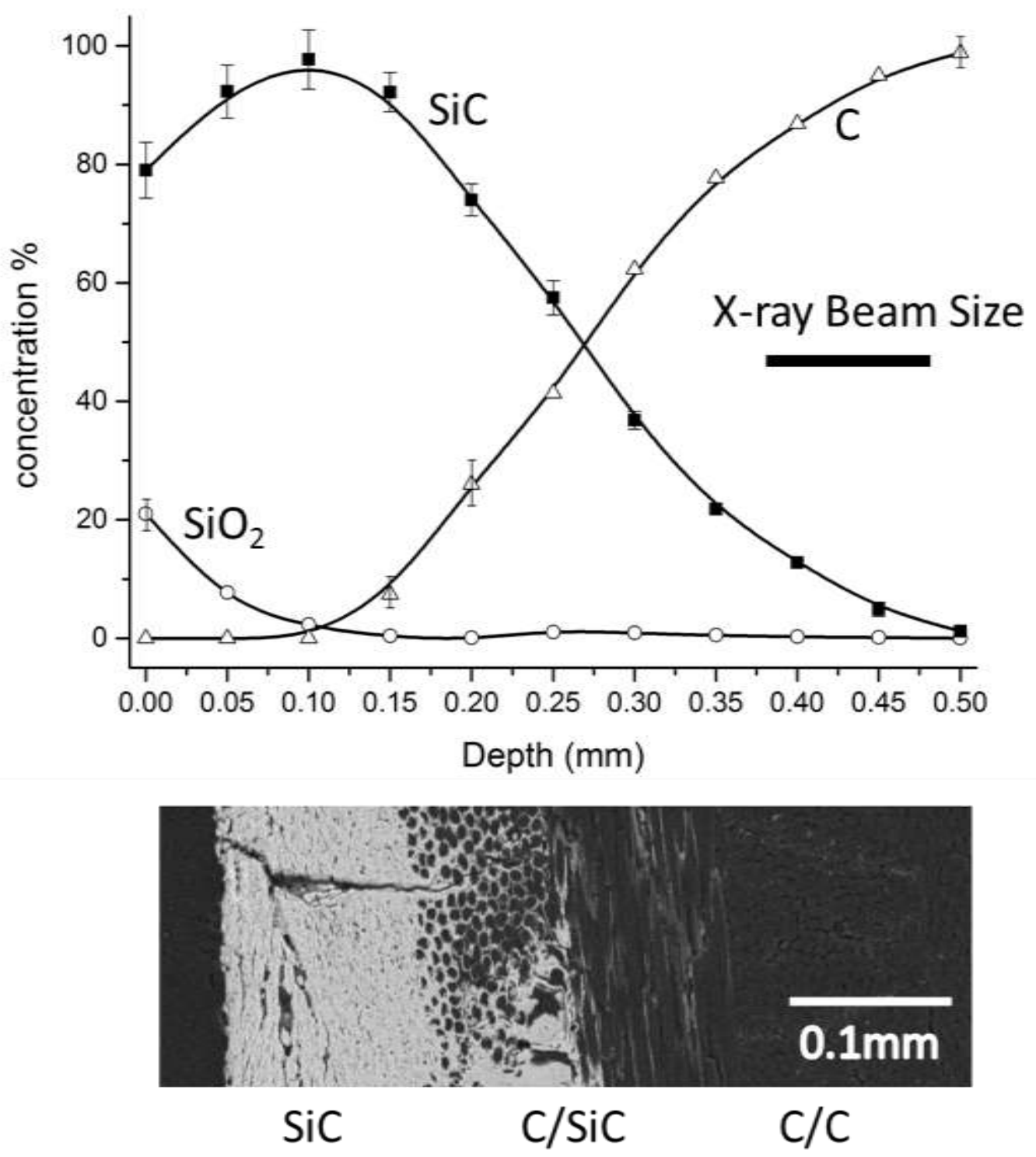

Fig. 12 

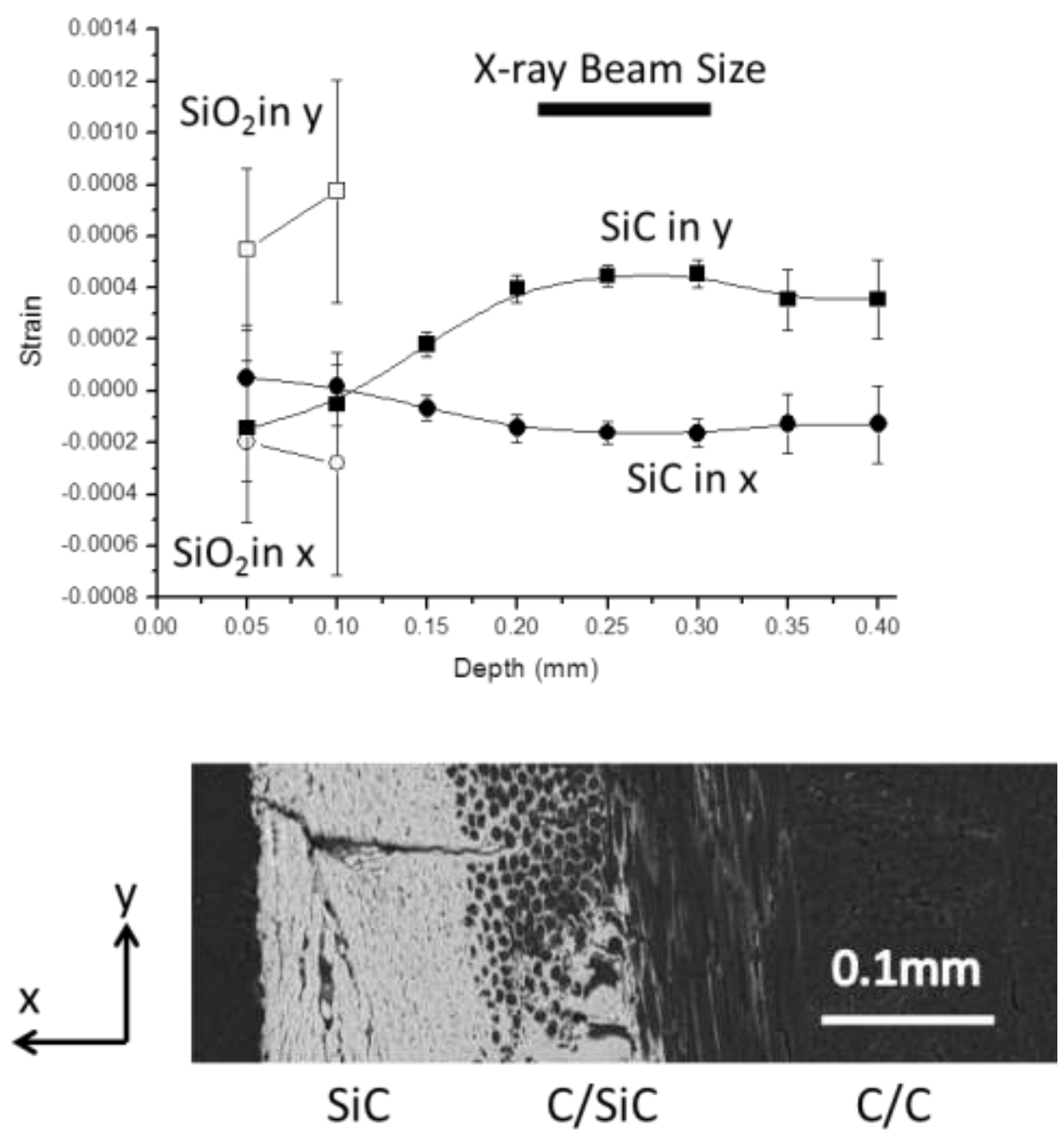

Fig. 13 

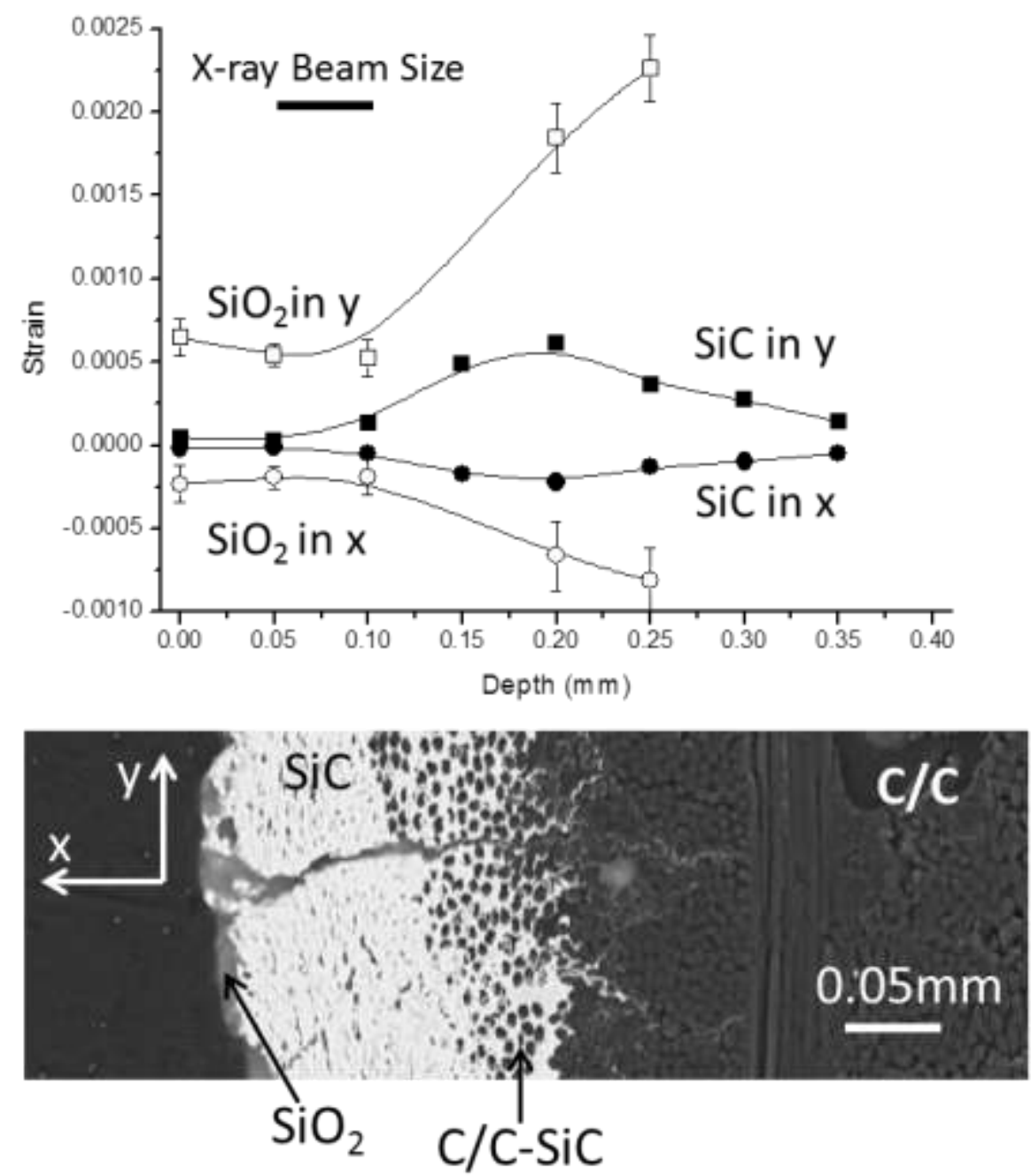

Fig. 14 


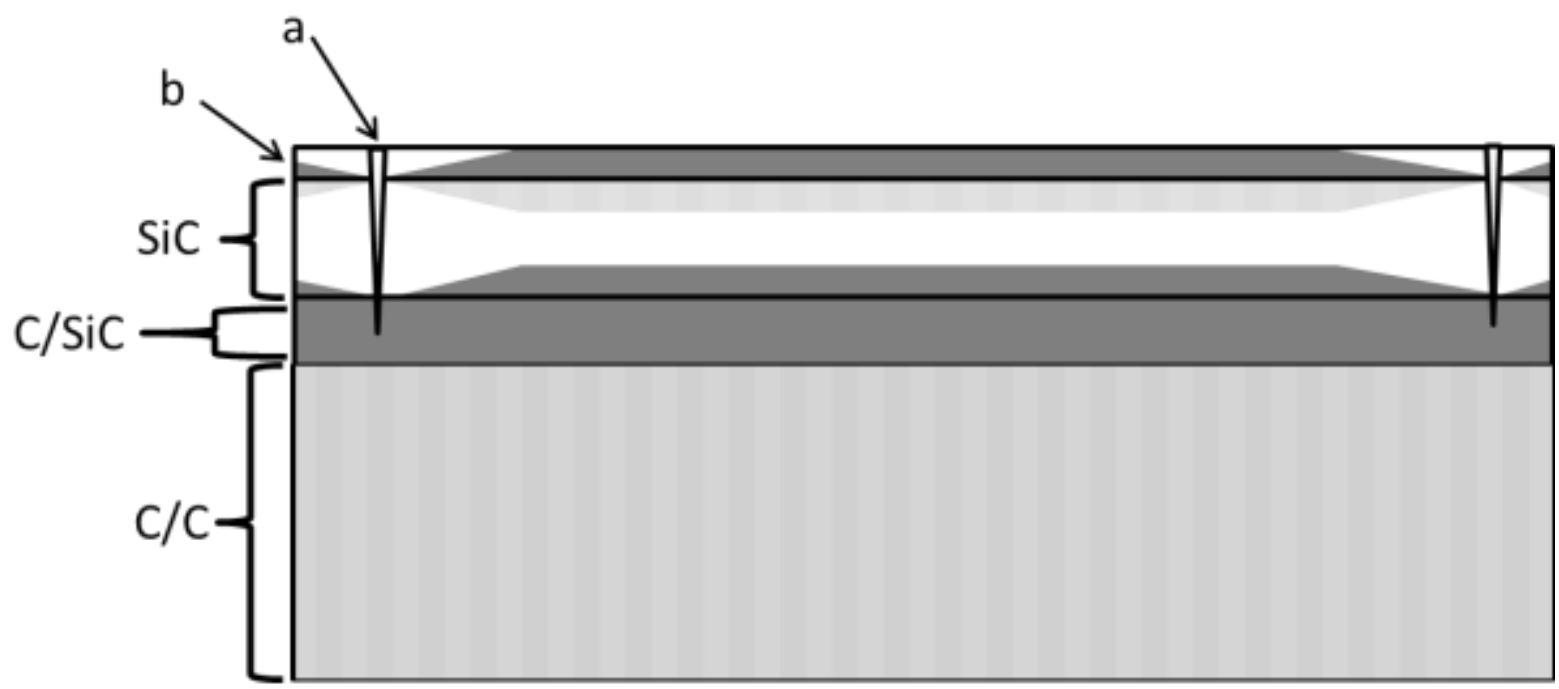

$\square$ Tension $\square$ Compression $\square$ Relaxed

Fig. 15 


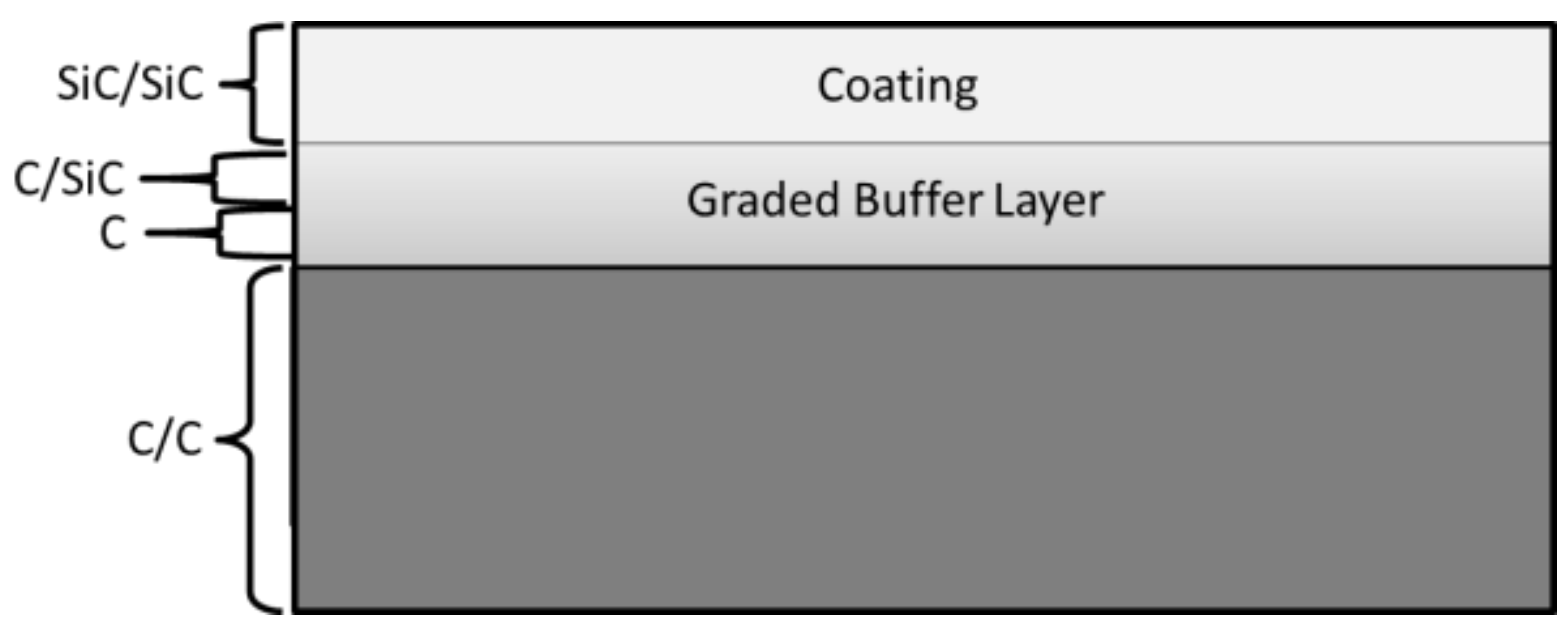

Fig 16 